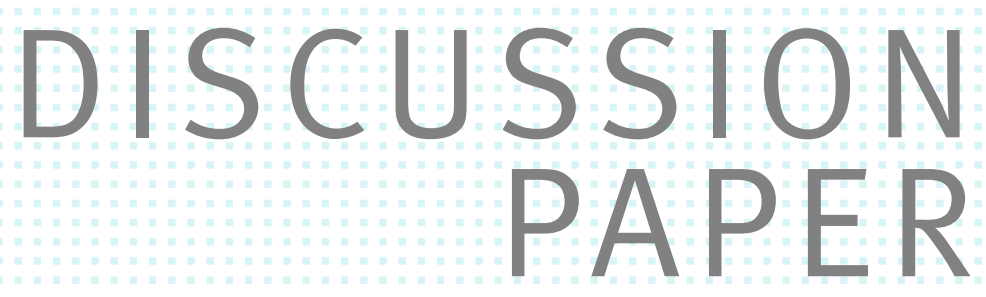

// NICOLAS FUGGER, VITALI GRETSCHKO AND MARTIN POLLRICH

\title{
Sequential Procurement with Limited Commitment
}




\title{
Sequential Procurement with Limited Commitment*
}

\author{
Nicolas Fuggerł Vitali Gretschkołand Martin Pollrich ${ }^{\S}$
}

August 6, 2019

\begin{abstract}
We analyze the problem of a buyer who chooses a supplier for a long-term relationship via an auction. The buyer lacks commitment to not renegotiate the terms of the contract in the long run. Thus, suppliers are cautious about the information revealed during the auction. We show theoretically and experimentally that first-price auctions perform poorly in terms of efficiency and buyer surplus. Suppliers may pool on a high bid to conceal information. Second-price auctions retain their efficient equilibrium and generate substantial surplus for the buyer. We demonstrate that optimal mechanisms require concealing the winning bid with a strictly positive probability.
\end{abstract}

\section{Introduction}

Firms are in long-term relationships with their suppliers. In past decades, auctions emerged as the dominant mechanisms for selecting suppliers and the terms of trade. However, in a long-term relationship, it is hard to commit to not renegotiating the initial terms of the contract that were set by the auction. ${ }^{1}$ The buyer can use the

${ }^{*}$ We thank Elena Katok, Peter Katuscak, Helene Mass, Marc Möller and the seminar participants at Aachen University, University of Bayreuth, University of Bielefeld, DICE, Humbold University, Industrieökonomischer Ausschuss, TU Munich, INFORMS Conference (Phoenix 2018) and the ZEW Workshop on Market Design for helpful comments and suggestions.

$\dagger$ ZEW Mannheim, nicolas.fugger@zew.de

$\ddagger$ ZEW Mannheim and University Mannheim, vitali.gretschko@zew.de

$\S$ University Bonn, martin.pollrich@uni-bonn.de

${ }^{1}$ Mueller et al. (2016) find in a survey among automotive buyers: "[Prices] are always precisely specified for the initial delivery period, e.g., one year. However, framework contracts foresee further delivery periods up to over the model lifetime. In such a contract, prices for ensuing periods are either pre-specified, with step-wise price reduction schedules to account for cost reductions via learning, or prices are renegotiated annually. In either case, price specifications are likely not to be binding. The OEM may enforce price renegotiation under breach of contract, especially in the context of negotiations preceding contractual arrangements for parts for a new car model." 
information revealed by suppliers during the initial auction in subsequent renegotiations. As suppliers' rents depend on their private information, they will be cautious about what they reveal in the auction. We study the performance of procurement mechanisms when the buyer cannot commit not to renegotiate terms of trade in the long-run.

Different auction formats reveal different amounts of information. In a first-price auction, if suppliers employ a separating bidding strategy, the buyer can fully back out the (cost-)type of the winning supplier by observing the resulting price, which is equal to the winner's bid. The buyer uses this information during the renegotiation, reducing the rent of the winning supplier. In a second-price auction ${ }^{2}$, the price is set by the runner-up. Given a monotone bidding strategy, observing the price merely reveals that the type of the winning supplier is below a cut-off. The winning supplier always maintains an informational advantage over the buyer in the renegotiation.

We demonstrate that if the profits at the time of renegotiation are high, suppliers pool on the same high bid in the first-price auction. In this case, the first-price auction fails to select an efficient supplier. In a second-price auction, such pooling is never an equilibrium outcome and the auction always selects an efficient supplier. If bidders pool, the first-price auction generates lower buyer surplus than the secondprice auction.

In general, the buyer surplus in the second-price auction is also not optimal. The optimal auction fine-tunes the trade-off between rent extraction and information release during the auction. We derive sufficient conditions such that the optimal auction is an $\alpha$-second-price auction. In the $\alpha$-second-price auction, the winner pays the bid of the runner-up just as in the second-price auction. However, his bid is revealed to the buyer with probability $\alpha$. At this, $\alpha$ is chosen such that maximal information is released without destroying the incentives to separate in the auction.

In a lab experiment, set up to compare the performance of first-price auctions and second-price auctions, we find substantial pooling in the first-price auction but not in the second-price auction. This results in a clear ranking in terms of efficiency of both formats.

Our results imply that if the buyer cannot commit not to renegotiate, second-price auctions robustly achieve efficient supplier selection and high buyer surplus. Firstprice auctions, perform poorly and should be used with caution. On a high level, we provide a foundation for privacy-preserving implementation of procurement auctions through, e.g., third parties, electronic platforms or decentralized encryption protocols.

\footnotetext{
${ }^{2}$ We assume that the buyer observes the price, but not the winner's bid. This is the case if the second-price auction is implemented as an English auction, which is the most common second-price format in practice.
} 
In procurement practice, contracts are usually a trade secret to protect the privacy of suppliers against their competitors and other buyers. We stress that such privacy is also of importance in the immediate buyer-supplier relationship.

Section 2 describes our baseline model with two periods. In the first period, a buyer procures from one of $n$ suppliers a project, which size is normalized to one. In period two, the buyer may negotiate an additional delivery of size $Q$ with the contract supplier selected in period one. ${ }^{3}$ The costs of delivering the project in period one are private information to the suppliers and can be either high or low. ${ }^{4}$ To select a contract supplier the buyer conducts an auction. Prior to the second period, the contract supplier draws a cost shock that is correlated with his cost in period one: low-cost suppliers are more likely to have lower costs in period two than high-cost suppliers. The shock captures, e.g., any learning effects, efficiency gains, or price changes of input factors. In period two, the buyer may employ any mechanism to fix the price and the probability of delivery for the additional quantity. That is, the buyer has full bargaining power within each of the two periods, but no possibility to commit between the periods.

We corroborate our model with a survey among procurement consultants. The average participant in the survey, during his or her career, participated in 77 projects and in sum negotiated over 10 billion EUR of purchasing volume. ${ }^{5}$ The median probability of the initial price agreement being renegotiated is reported to be 50 percent. The median duration of the initial price agreement is reported to be 24 months. This is about $20 \%$ of a typical lifetime of a project in the automotive industry. That is, commitment to future prices is not common and stakes are high at the time of renegotiation.

In Section 3 we analyze first-price and second-price auctions. We work our way backwards. In the second period, the buyer proposes the optimal mechanism given her (updated) belief after the initial auction. As she is facing only one supplier, the

\footnotetext{
${ }^{3}$ This is an absorbing exit condition as in Tirole (2016). Only the contract supplier is considered for the additional volume. This is a reasonable assumption for the procurement of complex projects and customized parts as those require high relationship-specific investments. In a survey of the automotive industry Mueller et al. (2016) argue that this is standard industry practice and identify six factors that lead to prohibitively high switching costs: specific production tools, process knowhow, intellectual property, qualification/validation costs, production capacity, production downtime. Even though buyers resort to multiple sourcing to avoid hold-up, we abstract from multiple sourcing in this paper. Multiple sourcing increases the buyer's bargaining power and makes the problem of private information revelation even more pronounced. Moreover, the suppliers would not only need to conceal the information from the buyer but also from their competitors.

${ }^{4}$ We consider more general type spaces in Section 7.

${ }^{5}$ We carried out the survey in December 2016 among 70 procurement consultants. The response rate was $48.6 \%$. The consultants of the questioned company sometimes work in teams, such that just summing the project experience and negotiated volume would overestimate the overall experience. As an orientation, in the years 2013-2016 the company as a whole delivered 600 projects with an overall purchasing volume of 70 billion EUR.
} 
optimal mechanism is a take-it-or-leave-it offer. If she is sufficiently sure to face a lowcost supplier, she will post a low take-it-or-leave-it offer that would not be accepted by a high-cost supplier. Vice versa, she will place a high offer if she is not sure enough to face a low-cost supplier. Thus, suppliers benefit from making the buyer believe that they have high cost. The larger the follow-up project $(Q)$ the larger this benefit.

In the first period, the auctions differ with respect to the information contained in the price. In the first-price auction, the price is equal to the winning bid. Thus, the buyer perfectly learns the bid of the contract supplier. In the second-price auction, the price is equal to the bid of the runner-up. Thus, the buyer learns only that the bid of the contract supplier was less than or equal to the first-period price.

We show that irrespective of the size of the follow-up project types separate in the second-price auction in every symmetric perfect Bayesian equilibrium. To gain some intuition suppose all suppliers pool on the same bid. This implies, that bidders end up in a tie. A supplier gains winning probability without sacrificing first-period profit by slightly undercutting the pooling bid. Such undercutting has no consequence in the second period as the price will be set by the pooling bid and the beliefs of the buyer do not change given the deviation. The same logic applies to any partial pooling. Hence, there is no pooling equilibrium in the second-price auction.

The situation in a first-price auction is quite different. If in equilibrium all suppliers pool on the same bid, a deviating bidder sets the price. This changes the buyer's belief and thus the contract supplier's second-period profit. When the size of the secondperiod $Q$ is sufficiently large, full pooling can be sustained in equilibrium. We derive all symmetric perfect Bayesian equilibria when the buyer uses a first-price auction. Equilibria can involve pooling, separating or partial-pooling depending on the size of the second period.

In Section 4, we compare the buyer surplus for both auction formats. Whenever the first-price auction exhibits a pooling equilibrium, the second-price auction generates a strictly larger buyer surplus. In the pooling equilibrium of the first-price auction, suppliers pool on a bid larger or equal to the highest bid in the second-price auction. Thus, the buyer surplus in the first period is smaller in a first-price auction. As pooling does not reveal any additional information to the buyer, the second-period surplus is also smaller. Matters are different in a separating equilibrium of the firstprice auction. The highest bid is lower or equal to the highest bid in the second-price auction. Moreover, a separating equilibrium reveals all available information about the cost type to the buyer. Thus, also the surplus in the second period is larger.

Overall, the question whether the second-price auction or the first-price auction generates larger buyer surplus boils down to the question whether the first-price auction exhibits a pooling or a separating equilibrium. For large follow-up projects (large 
$Q$ ), we provide sufficient conditions such that the pooling equilibrium is the unique equilibrium of the first-price auction. In those cases, the first-price auction generates a smaller buyer surplus than the second-price auction. For small follow-up projects (small $Q$ ) the separating equilibrium is the unique equilibrium and thus the first-price auction generates more buyer surplus.

Our survey among procurement practitioners suggests that, at least in the automotive industry, $Q$ is rather large as the initial contract only covers about $20 \%$ of the typical lifetime of the project. Thus, our results imply that first-price auctions should be used with caution in the procurement of complex goods and services. In particular, if the auction results in a long-term relationship with early renegotiation, second-price auctions yield better outcomes.

In Section 5, we analyze the buyer-surplus maximizing mechanism. In all generality, in such a dynamic environment, this is a very challenging task. Thus, we restrict ourselves to the cases where it is always optimal for the buyer to procure the good. These are the cases in which the value of the project is substantially higher than the potential costs of the suppliers. This is a reasonable assumption for the procurement of complex goods and services. Consider, for example, the automotive industry. When procuring a steering wheel for a new model, it is not reasonable for the buyer to stop the planning of the model just because she was not able to achieve the optimal cost savings on the steering wheel.

We show that if the buyer's value $R$ of the project is sufficiently high, she faces no commitment problem. That is, with the right information management, she achieves the optimal full-commitment surplus even without commitment power. First, consider the case in which second-period costs are drawn from the same interval, irrespective of the first-period costs. When $R$ is large, the optimal price in the second period does not depend on the buyer's belief: the buyer proposes the upper bound of the common support of the cost distribution. Thus, the main trade-off between information revelation and rent extraction in the first period is not relevant and a second-price auction maximizes the buyer surplus.

With different supports of the second-period cost distribution, information design becomes relevant. If the buyer is sure to face a certain type in period two, she will offer his individual upper bound. Thus, the offer of the buyer is sensitive to her belief. In this case, a second-price auction may be sub-optimal. When the auction results in a high price, the buyer is uncertain whether she faces a low-cost or high-cost supplier. This may induce a second-period price which some high-cost suppliers reject in period two. Any rejection destroys buyer surplus if $R$ is sufficiently large. Revealing whether the winner's bid was lower than the winner's price with probability $\alpha$ corrects the belief of the buyer without sacrificing second-period rents. Now, whenever the buyer 
does not observe the winning bid she becomes more pessimistic about the contract supplier's type and increases her second-period offer. With the appropriate choice of $\alpha$, the increased second-period offer is accepted with probability one.

The optimal mechanism requires a non-trivial way to handle the information contained in the bid vector. In practice, such fine control of information would need the involvement of third parties (intermediaries). Some recent advances in information technology also allow implementing such information revelation without the use of intermediaries. Decentralized encryption gives bidders the opportunity to send encrypted bids in a way that the public key merely allows calculating the outcome of the auction but not the individual bids (Brandt, 2010).

In Section 6 we present an experimental comparison of first-price auctions and second-price auctions. ${ }^{6}$ In line with the theory, we find substantial pooling the firstprice auction. This pooling behavior is significantly more pronounced than in the second-price auction and becomes more frequent when suppliers gain experience.

In Section 7 we provide extensions of our baseline model and show the robustness of our results. First, we allow for some bargaining power of the contract supplier in period two. Increasing the bargaining power of the supplier renders his private information less relevant for the renegotiation. As before, the first-price auction may exhibit pooling, partial-pooling or separating equilibria. In the second-price auction the cost-types still separate. In a pooling equilibrium, the first-price auction is inefficient and generates smaller buyer surplus than the second-price auction. However, as information release becomes less relevant, the pooling equilibrium of the first-price auction becomes harder to sustain.

Second, we extend the type space to more than two types. We show that full pooling constitutes an equilibrium in the first-price auction whenever the secondperiod project becomes sufficiently large. The second-price auction always leads to separation and reasonable buyer surplus. Thus, as in the baseline model, the firstprice auction performs poorly as compared to the second price auction if the follow-up project is sufficiently large. However, in contrast to the baseline model, a separating equilibrium of the first-price auction fails to exist, as soon as there are at least three first-period cost types. Thus, our main conclusions remain intact: the second-price auction is well behaved, achieves an efficient allocation in period one and reasonable buyer surplus; while the first-price auction performs poorly.

We review the related literature in Section 8. Our work is related to two strands

\footnotetext{
${ }^{6}$ Sometimes theoretical findings are overturned by experiments (Davis et al., 2010, 2014) as optimal equilibrium behavior is hard to derive for subjects in the lab. In the case at hand, it might be hard for suppliers to anticipate the impact of their behavior on buyers offers in second-period. Our experiment is designed to provide a simple test whether such a level of reasoning is behaviorally relevant.
} 
of literature. First, auctions and mechanism design with limited commitment. Most of those models consider negative selection where the interaction only continues if the object is not allocated. We consider positive selection, where the interaction only continues if the object is allocated. Second, we connect to the literature on auctions and mechanism design with aftermarkets. The crucial component in those models is the information available to the aftermarket. Either the information release is exogenously given or the designer can design arbitrary information regimes. Our model is the intermediate case. As the designer participates in the aftermarket, she cannot rule out some information release via the allocation rule and the observable price. The mechanism, however, can - but does not have to - release additional information.

\section{Model}

In each of two periods, a buyer (she) awards a contract to one of $n \geq 2$ suppliers (he). The second contract can only be fulfilled by the winner of the first contract. ${ }^{7}$ In period $t=1,2$ the buyer demands a quantity $Q^{t}$. To economize on notation we normalize $Q^{1}$ to one and denote by $Q:=Q^{2} / Q^{1}>0$ the relative quantity in the second period. In each period the buyer has a constant value of $R>0$ per unit of delivery. That is, if the buyer purchases in period $t$ at per-unit price $p^{t}$, her profit is $Q^{t} \cdot\left(R-p^{t}\right){ }^{8}$

Period 1. A supplier can be of two types, $\theta=l$ or $\theta=h .^{9}$ Type $\theta$ 's cost of producing one unit in period one is $c_{\theta}$, where $0<c_{l}<c_{h}<R$. We will call a $h$-type a high-cost supplier and a $l$-type a low-cost supplier. Types are drawn independently and identically at the beginning of period one and are a supplier's private information. Denote $\mu_{1} \in(0,1)$ the prior probability that a supplier's type is $l$.

Suppliers submit bids $b^{i} \in \mathbb{R}$ in a reverse auction. Let $\mathbf{b}=\left(b^{1}, \cdots, b^{n}\right)$ denote the vector containing all bids. The supplier placing the lowest bid wins the first contract. Ties are broken at random. The winner receives a payment $p$ determined in the reverse auction. That is, if supplier $i$ wins the auction at price $p$ his profit is $p-c^{i}$. We consider first-price and second-price auctions. In a first-price auction, the price is determined by the winning bid. In a second-price auction, the price is determined by the second-lowest bid. After the auction, the buyer merely observes the winner of the auction and the price at which the auction concluded. The buyer does not observe all

\footnotetext{
${ }^{7}$ See Footnote 3 for an elaboration on this assumption on absorbing exit.

${ }^{8}$ We formulate the procurement project in terms of delivered quantity. In an alternative interpretation the buyer purchases two projects of unequal sizes and values.

${ }^{9}$ Our main findings are robust to introducing more general type spaces, see the discussion in Section 7 .
} 
of the bids placed during the auction. ${ }^{10}$

After observing the outcome of the auction the buyer updates her belief. The only available (public) information is the price $p$ the winning bidder receives. We denote $\mu_{2}(p)$ the buyer's belief regarding the winner's type, i.e. the probability that the winner is a low-cost type.

Period 2. At the beginning of the second period, the winning supplier $i$ privately draws the second period cost $c$ from the distribution $F_{\theta}(c)$ on $\left[\underline{c}_{\theta}, \bar{c}_{\theta}\right]$, where $\theta$ denotes the winning bidder's type and $R>\bar{c}_{\theta} \cdot{ }^{11}$ The buyer then uses any mechanism ${ }^{12}$ to decide on the offer to the contract supplier for the delivery of the second-period quantity $Q$. If the buyer purchases a quantity $Q$ at a per-unit price $P$ in the second period, her profit is $Q \cdot(R-P)$ and the contract supplier's profit is $Q \cdot(P-c)$.

To avoid pathological cases and ensure that the outcome in period two is unique we make the following assumptions regarding the distribution of second-period costs.

Assumption 1. The following holds true for all $\mu \in[0,1]$ and all $c$ :

1. $F_{\theta}$ has strictly positive density on its support $\left[\underline{c}_{\theta}, \bar{c}_{\theta}\right]$ for any $\theta$.

2. $F_{h}(c)$ dominates $F_{l}(c)$ in terms of the reverse hazard rate. That is,

$$
\frac{f_{h}(c)}{F_{h}(c)}>\frac{f_{l}(c)}{F_{l}(c)}
$$

3. The updated hazard rate,

$$
\frac{(1-\mu) F_{h}(c)+\mu F_{l}(c)}{(1-\mu) f_{h}(c)+\mu f_{l}(c)}
$$

is non-decreasing in $c$.

The second assumption implies that being the low-cost type in period one translates into a higher probability of having lower costs in period two. It implies $\bar{c}_{l} \leq \bar{c}_{h}$

\footnotetext{
${ }^{10}$ Since losing suppliers exit, the assumption on observability of the bid vector is inconsequential regarding losing bids. In a first-price auction, in which the price is equal to the winning bid, this assumption is vacuous. Thus, the assumption boils down to the buyer not observing the winning bid in a second-price auction. This is the case e.g. if the second-price auction is implemented as an English auction which is the standard in practice.

${ }^{11} \mathrm{~A}$ redrawing of the cost captures, e.g., learning-by-doing, or cost-changes of input factors. With changing second-period costs the buyer can benefit from multiple-sourcing, as in Burguet (1996). We abstract from this possibility to focus on the pure effect of renegotiation. See also Footnote 3.

${ }^{12}$ We refrain from formally introducing abstract mechanisms at this point. We show in Section 3 that it is optimal for the buyer to simply post a price to the contract supplier. Moreover, in Section 7 we show that the main results remain intact if the contract supplier has bargaining power in period two.
} 
and $\underline{c}_{l} \leq \underline{c}_{h}$, as well as first-order stochastic dominance, $F_{l}(c) \geq F_{h}(c)$ for all $c$. The third assumption is a standard assumption that ensures that virtual costs are strictly increasing for every belief of the buyer in period two. It ensures the monotonicity of second-period rents (See Lemma 2).

\section{Timing}

1. Suppliers learn their first-period cost $c^{1}, \ldots, c^{n}$.

2. Suppliers submit bids $b^{1}, \ldots, b^{n}$.

3. The buyer observes the price $p$ of the auction and updates her belief to $\mu_{2}(p)$.

4. Profits from period one realize.

5. The contract supplier learns his second-period cost $c$.

6. The buyer proposes a mechanism.

7. The contract supplier participates in the mechanism.

8. Second-period profits realize.

\section{Equilibria of first-price and second-price auctions}

In this section, we characterize the equilibria of the first-price and second-price auctions. We work our way backward starting with the analysis of optimal second-period offers. We derive a reduced-form second-period profit function for the suppliers and characterize all symmetric equilibrium bidding strategies in the respective auction formats.

\subsection{The second period}

In the second period, the buyer uses a take-it-or-leave-it offer without loss of generality. The following lemma characterizes the optimal offers.

Lemma 1. Let $\mu_{2}$ be the belief of the buyer after observing the first-period price. Then the optimal mechanism in the second period is to make a take-it-or-leave-it offer $P\left(\mu_{2}\right)$ that is given by the solution to

$$
R-P\left(\mu_{2}\right)-\frac{\mu_{2} F_{l}\left(P\left(\mu_{2}\right)\right)+\left(1-\mu_{2}\right) F_{h}\left(P\left(\mu_{2}\right)\right)}{\mu_{2} f_{l}\left(P\left(\mu_{2}\right)\right)+\left(1-\mu_{2}\right) f_{h}\left(P\left(\mu_{2}\right)\right)}=0
$$

if the solution exists and by $P\left(\mu_{2}\right)=\bar{c}_{h}$ otherwise. ${ }^{13}$

\footnotetext{
${ }^{13}$ Assumption 1 guarantees that if a solution exists, it is unique.
} 
Proof. Given Assumption 1 this result is immediate from, e.g., Myerson (1981).

The optimal mechanism awards the project to the contract supplier whenever the virtual surplus of the buyer, as defined by substituting $c$ for $P\left(\mu_{2}\right)$ into the left-hand side of (1), is larger than zero. This is achieved by the optimal take-it-or-leave-it offer $P\left(\mu_{2}\right)$ as stated in Lemma 1.

Definition 1. We denote by

$$
\pi_{2}\left(c_{\theta}, \mu_{2}\right)=\mathbb{E}_{\theta}\left[\max \left\{P\left(\mu_{2}\right)-c, 0\right\}\right]
$$

the second period per-unit profit of a winning supplier given his first period cost is $c_{\theta}$ for $\theta \in\{l, h\}$ and the second-period belief of the buyer is $\mu_{2}$.

The following lemma establishes that the more likely the buyer thinks that she is facing the low-cost supplier, the lower she will choose the offer for the second period. This is useful in deriving the equilibrium of the auctions in period one.

Lemma 2. The optimal take-it-or-leave-it offer $P\left(\mu_{2}\right)$ and the supplier's second-period profit $\pi_{2}\left(\cdot, \mu_{2}\right)$ are decreasing in $\mu_{2}$.

Proof. The proof is relegated to the appendix.

\subsection{The first period}

Before we turn our attention to the equilibrium bidding in the first period, we introduce some notation with respect to the bidding strategies of the bidders. Throughout the analysis, our solution concept will be symmetric perfect Bayes-Nash equilibrium and thus we will not index bidding strategies by bidder. We will denote by $\mathcal{B}_{\theta}(\cdot)$ the distribution function of the mixed strategy of a bidder with first-period type $\theta \in\{l, h\}$. That is, $\mathcal{B}_{\theta}(b)$ denotes the probability that his bid will be below $b$. Let $\underline{b}_{\theta}$ denote the infimum and $\bar{b}_{\theta}$ the supremum of the support of $\mathcal{B}_{\theta}(\cdot)$. Moreover, $b_{\theta}(\cdot)$ denotes the density of $\mathcal{B}_{\theta}(\cdot)$. Whenever the bidder uses a pure strategy we will slightly abuse notation and write that the bidder places a bid of $b_{\theta}$.

\subsubsection{Second-price auction}

In a second-price auction, the price $p$ in period one is equal to the second-lowest bid. Proposition 1 characterizes the unique symmetric equilibrium bidding strategies. The second-price auction in our setting retains the well known properties from its static counterpart. That is, in equilibrium bidders place bids equal to their expected surplus from procurement. 
Proposition 1. In a second-price auction, a symmetric equilibrium exists. In any symmetric equilibrium, bidding strategies are as follows. A high-cost supplier $(\theta=h)$ bids

$$
b_{h}=c_{h}-Q \cdot \pi_{2}\left(c_{h}, \frac{n \mu_{1}}{n \mu_{1}+1-\mu_{1}}\right) .
$$

A low-cost supplier $(\theta=l)$ bids

$$
b_{l}=c_{l}-Q \cdot \pi_{2}\left(c_{l}, 1\right)
$$

After observing the first-period price $p$ the buyer updates her belief to ${ }^{14}$

$$
\mu_{2}(p)= \begin{cases}\frac{n \mu_{1}}{n \mu_{1}+1-\mu_{1}} & p=b_{h} \\ 1 & \text { else }\end{cases}
$$

The buyer offers $P\left(\mu_{2}(p)\right)$ in the second period. The contract supplier accepts the second-period offer whenever $c \leq P\left(\mu_{2}(p)\right)$.

Proof. The proof is relegated to the appendix.

In a second-price auction, the price is set by the runner-up. Conditional on winning, a bidder cannot influence the buyer's belief. Any bid that leaves the high-cost supplier with a positive profit cannot be part of a symmetric equilibrium bidding strategy. Such a supplier could deviate to a lower bid increasing his profit in the first period without changing his second-period profit. Once the bid of the high-cost supplier is fixed the same is true for the low-cost supplier. To see this, suppose a potential symmetric equilibrium would prescribe that a low-cost supplier places a bid that leaves him positive profit even if he faces another low-cost supplier with the same bid. In this case, he could slightly undercut this bid increasing his expected profit in the first period without sacrificing any profit in the second period.

\subsubsection{First-price auction}

In the first-price auction, the price $p$ is equal to the lowest bid. The buyer observes the price and thereby the bid of the winner. The direct effect of one's own bid in period one on the (expected) profit in period two creates incentives for pooling. We provide a necessary and sufficient condition such that there exists a pooling equilibrium resulting in poor performance of first-price auctions. ${ }^{15}$

\footnotetext{
${ }^{14}$ In a second-price auction, off-path beliefs of the principal do not matter (see the proof of Proposition 1). Thus, different off-path beliefs lead to the same on-path behavior.

${ }^{15}$ In Section 7 we show that the existence of a pooling equilibrium extends to more general type spaces.
} 


\section{Pooling equilibrium}

The most interesting case arises if it is beneficial for a bidder with the low-cost type to conceal his type in the auction and pool with the high-cost type.

Proposition 2 (Pooling equilibrium). If and only if there exists $a b$ with

$$
\begin{aligned}
b & \leq c_{l}-Q \pi_{2}\left(c_{l}, \mu_{1}\right)+\frac{n}{n-1} Q\left(\pi_{2}\left(c_{l}, \mu_{1}\right)-\pi_{2}\left(c_{l}, 1\right)\right), \\
b & \leq c_{h}-Q \pi_{2}\left(c_{h}, \mu_{1}\right)+\frac{n}{n-1} Q\left(\pi_{2}\left(c_{h}, \mu_{1}\right)-\pi_{2}\left(c_{h}, 1\right)\right), \\
b & \geq c_{h}-Q \pi_{2}\left(c_{h}, \mu_{1}\right),
\end{aligned}
$$

pooling equilibria exist in the first-price auction. In a pooling equilibrium, all bidders irrespective of their type place the same bid $b_{h}=b_{l}=b$.

Proof. The proof is relegated to the appendix.

Low-cost types pool whenever the loss in profits, $\pi_{2}\left(c_{l}, \mu_{1}\right)-\pi_{2}\left(c_{l}, 1\right)$, in the secondperiod from being identified as a high type is large enough. Note that the first-price auction in our setting may exhibit many pooling equilibria. The equilibrium price is set by the high-cost type. Due to the uncertainty about the second-period costs, he can earn strictly positive profits in equilibrium. If a high-cost type undercuts an equilibrium price that leaves him a positive profit, the buyer believes to face the low-cost type. The second-period profits of the high-cost type jump downwards. Thus, prices above the level of zero profits for the high-cost type can be sustained in equilibrium. This is different in a standard first-price auction without a second period where high-cost types compete their profits down to zero.

Ultimately, we are interested in the comparison of the buyer surplus of the firstprice and second-price auction. To this end, we are interested in the comparative statics of an increase in $Q$, the size of the second period. For the revenue comparison (see Section 4) we consider the pooling equilibrium that generates the highest possible buyer surplus. That is, the pooling equilibrium, in which bidders place the lowest possible bid $b_{h}=c_{h}-Q \cdot \pi_{2}\left(c_{h}, \mu_{1}\right)$. The conditions for the existence of such an equilibrium result from conditions (2) and (4) and are characterized in the following corollary.

Corollary 1. If and only if

$$
\frac{1}{n}\left(\pi_{2}\left(c_{l}, \mu_{1}\right)-\pi_{2}\left(c_{h}, \mu_{1}\right)\right)>\pi_{2}\left(c_{l}, 1\right)-\pi_{2}\left(c_{h}, \mu_{1}\right),
$$

there exists $Q_{\text {pool }}$ such that for all $Q \geq Q_{\text {pool }}$ the first-price auction has a pooling equilibrium. 
Increasing the size of the second period affects the bidders' payoff both on and off the equilibrium path. On the path, the second-period profits increase. However, the equilibrium bid reduces as high-cost suppliers compete away their increased secondperiod gains of $Q \cdot \pi_{2}\left(c_{h}, \mu_{1}\right)$. The effect on a low-cost type's payoff is strictly positive. His second-period profit increases at a larger rate than the profit of the high-cost type which offsets the reduced equilibrium bid.

Off-path, more aggressive bidding lowers first-period profits at the rate of $n$. $\pi_{2}\left(c_{h}, \mu_{1}\right)$, while second-period profits increase at the rate of $n \cdot \pi_{2}\left(c_{l}, 1\right)$. Depending on the difference, the effect can go either way. If the effect is negative, condition (5) holds trivially. If the effect is positive, condition (5) holds if and only if the increase in on-path payoffs is stronger than the increase in off-path payoffs. ${ }^{16}$

\section{Separating equilibrium}

For a complete characterization, we now derive all possible symmetric equilibria of the first-price auction. Depending on the initial parameters, the first period can be sufficiently attractive such that second-period profits are not attractive enough to induce pooling.

Proposition 3 (Separating equilibrium). If and only if there exist $b$ with

$$
\begin{aligned}
& b \geq c_{l}-Q \cdot \pi_{2}\left(c_{l}, 0\right)+\frac{n}{n-1} \cdot Q \cdot\left(\pi_{2}\left(c_{l}, 0\right)-\pi_{2}\left(c_{l}, 1\right)\right), \\
& b \leq c_{h}-Q \cdot \pi_{2}\left(c_{h}, 0\right)+\frac{n}{n-1} \cdot Q \cdot\left(\pi_{2}\left(c_{h}, 0\right)-\pi_{2}\left(c_{h}, 1\right)\right), \\
& b \geq c_{h}-Q \cdot \pi_{2}\left(c_{h}, 0\right),
\end{aligned}
$$

separating equilibria exist in the first-price auction.

In a separating equilibrium, high-cost suppliers bid $b_{h}=b$. Low-cost suppliers randomize on the interval $\left[\underline{b}_{l}, b\right)$ according to the distribution

$$
\mathcal{B}_{l}(\widetilde{b})=1-\left(\frac{\underline{b}_{l}+Q \pi_{2}\left(c_{l}, 1\right)-c_{l}}{\mu_{1}^{n-1}\left(\widetilde{b}+Q \pi_{2}\left(c_{l}, 1\right)-c_{l}\right)}\right)^{\frac{1}{n-1}}+\frac{1-\mu_{1}}{\mu_{1}}
$$

with $\underline{b}_{l}$ given by

$$
\underline{b}_{l}=\left(1-\mu_{1}\right)^{n-1} \cdot\left(b-c_{l}\right)-c_{l}+\left(\left(1-\mu_{1}\right)^{n-1}-1\right) \cdot Q \cdot \pi_{2}\left(c_{l}, 1\right) .
$$

Proof. The proof is relegated to the appendix.

\footnotetext{
${ }^{16}$ With persistent types, that is, if second-period costs are the same as first-period costs, we have that $\pi_{2}\left(c_{l}, 1\right)=\pi_{2}\left(c_{h}, \mu_{1}\right)=0 \leq \pi_{2}\left(c_{l}, \mu_{1}\right)$. Consequently, (5) is satisfied and pooling equilibria exist as soon as $Q$ becomes sufficiently large.
} 
Similar to pooling equilibria, potentially many separating equilibria exist. If the high-cost type was to undercut his equilibrium bid, the buyer believes to face a lowcost type. Thus, the second-period profits of the high-cost type make a jump downwards. Prices above the level of zero profits for the high-cost type can be sustained in equilibrium.

\section{Corollary 2. If}

$$
n\left(\pi_{2}\left(c_{l}, 1\right)-\pi_{2}\left(c_{h}, 1\right)\right) \leq \pi_{2}\left(c_{l}, 0\right)-\pi_{2}\left(c_{h}, 0\right)
$$

a separating equilibrium of the first-price auction exists for all $Q$. Otherwise, there exists a $Q_{\text {sep }}$ such that a separating equilibrium only exists if $Q \leq Q_{\text {sep }}$.

The result directly follows from comparing the conditions in Proposition 3. Conditions (7) and (8) are always simultaneously fulfilled for some $b$. Whenever $Q$ is small, condition (8) already implies condition (6). To see this, consider the case $Q=0$. That is, a static first-price auction in which a separating equilibrium always exists. Perturbing the problem with a small $Q$ does not impede the existence of a separating equilibrium.

\section{Partial pooling equilibrium}

A pure pooling and a pure separating equilibrium may fail to exist. In this case, a partial-pooling equilibrium exists.

Proposition 4 (Partial pooling equilibrium). If and only if there exist $\mu \in\left(0, \mu_{1}\right)$ and $b$ with

$$
\begin{aligned}
& b=c_{l}-Q \cdot \pi_{2}\left(c_{l}, \mu\right)+\frac{n}{n-1} \cdot Q \cdot\left(\pi_{2}\left(c_{l}, \mu\right)-\pi_{2}\left(c_{l}, 1\right)\right), \\
& b \leq c_{h}-Q \cdot \pi_{2}\left(c_{h}, \mu\right)+\frac{n}{n-1} \cdot Q \cdot\left(\pi_{2}\left(c_{h}, \mu\right)-\pi_{2}\left(c_{h}, 1\right)\right), \\
& b \geq c_{h}-Q \cdot \pi_{2}\left(c_{h}, \mu\right),
\end{aligned}
$$

partial pooling equilibria exist in the first-price auction. In a partial pooling equilibrium, high-cost suppliers bid $b_{h}=b$. Low-cost suppliers bid $b_{h}$ with probability $p_{\mu}$ and with probability $1-p_{\mu}$ randomize on the interval $\left[\underline{b}_{l}, b\right)$ according to the distribution

$$
\mathcal{B}_{l}(\widetilde{b})=1-\left(\frac{\underline{b}_{l}+Q \cdot \pi_{2}\left(c_{l}, 1\right)-c_{l}}{\left(1-p_{\mu}\right)^{n-1} \cdot \mu_{1}^{n-1} \cdot\left(\widetilde{b}+Q \cdot \pi_{2}\left(c_{l}, 1\right)-c_{l}\right)}\right)^{\frac{1}{n-1}}+\frac{1-\mu_{1}+p_{\mu} \cdot \mu_{1}}{\left(1-p_{\mu}\right) \cdot \mu_{1}}
$$


with $\underline{b}_{l}$ given by

$$
\begin{array}{r}
\underline{b}_{l}=\left(1-\mu_{1}+p_{\mu} \cdot \mu_{1}\right)^{n-1} \cdot b_{h}+\left(\left(1-\mu_{1}+p_{\mu} \cdot \mu_{1}\right)^{n-1}-1\right) \cdot Q \cdot \pi_{2}\left(c_{l}, 1\right) \\
-\left(\left(1-\mu_{1}+p_{\mu} \cdot \mu_{1}\right)^{n-1}+1\right) \cdot c_{l}
\end{array}
$$

and $p_{\mu}$ given by

$$
p_{\mu}=\frac{\mu}{1-\mu} \cdot \frac{1-\mu_{1}}{\mu_{1}} .
$$

Proof. The proof is relegated to the appendix.

Partial pooling equilibria are an intermediate case between separating and full pooling equilibria. Partial pooling arises whenever the second-period payoff from imitating the high-cost type is too large to induce separation but not large enough to deter undercutting a complete pool. Partial pooling changes the belief of the buyer following bid $b_{h}$ to balance the incentives.

We have now characterized three types of equilibria. The following proposition establishes that at least one of these equilibria always exists and rules out other equilibria.

Proposition 5. A symmetric equilibrium of the first-price auction always exists. Every symmetric equilibrium is either pooling, separating or partial pooling as characterized in Propositions $2-4$.

Proof. The proof is relegated to the appendix.

The crucial point in proving Proposition 5 is to show the monotonicity of bidding strategies. A priori we cannot rule out that the buyer believes to face a high-cost type if she observes lower bids. Thus, both types, in principle, may place lower bids if this induces a switch of beliefs and higher second-period payoffs.

\section{Buyer surplus comparison of the first-price and second-price auction}

The question of buyer-surplus comparison of the first-price auction and the secondprice auction is delicate as the surplus in the first-price auction depends on equilibrium selection. We show that revenue equivalence fails and the first-price auction performs worse than the second-price auction in every equilibrium if the follow-up project is sufficiently large.

Lemma 3. In every pooling equilibrium of the first-price auction the buyer surplus is higher in the second-price auction than in the first-price auction. 
Proof. The proof is relegated to the appendix.

In a pooling equilibrium, the first-price auction performs worse than the secondprice auction in two dimensions. First, types do not separate. No information is revealed about the supplier's type. Thus, the buyer extracts less surplus in the second period. Second, the high-cost type is pooled with the low-cost type. Thus, in the second period, he receives a more aggressive offer and a lower profit. This leads to less aggressive bids by the high-cost type in the first period.

Lemma 3 provides a sharp revenue ranking of both auction formats whenever every equilibrium of the first-price auction is a pooling equilibrium. We focus on the size of the second period $Q$ and provide the following proposition.

Proposition 6. If condition (5) holds, there exists a $\bar{Q}$ such that for all $Q>\bar{Q}$ every equilibrium of the first-price auction yields lower buyer surplus than the second-price auction.

Proof. The proof is relegated to the appendix.

When condition (5) is satisfied, Corollary 1 ensures that a pooling equilibrium exists for large values of $Q$. We show that, in this case, no other type of equilibrium exists.

In Section 7 we discuss that the results on the existence of pooling equilibria and the buyer-surplus ranking are robust to extensions to general type spaces. Whenever there exist other equilibria, the first-price auction may outperform the second-price auction. However, as we discuss in Section 7, the existence of other equilibria breaks down as soon as the type space is extended beyond two types.

Proposition 7. In every separating equilibrium with the highest buyer surplus, i.e., $b_{h}=c_{h}-Q \cdot \pi_{2}\left(c_{h}, 0\right)$, the buyer surplus is higher in the first-price auction than in the second-price auction.

Proof. The proof is relegated to the appendix.

In the separating equilibrium with the highest buyer surplus, the first-price auction outperforms the second-price auction in two dimensions. First, due to the complete separation, the buyer receives superior information after period one and thus extracts more surplus in the second period. Second, in the separating equilibrium of the firstprice auction the high-cost type is perfectly identified after period one, while in the second-price auction this can never happen. ${ }^{17}$ Consequently, the buyer's second-period price offer when the auction ends at a high price is higher in the first-price auction.

\footnotetext{
${ }^{17}$ Recall the price in the second-price auction is set by the runner-up. The probability that the winner placed a bid strictly below the price is never zero.
} 
Thus, in a first-price auction a high-cost supplier expects a higher profit in the second period which in turn leads to more aggressive bidding. As the bid of the high-cost type sets the upper bound of the bid distribution, the separating equilibrium also yields higher buyer surplus in the first period. Whenever the second period contract is relatively small Corollary 2 ensures that a separating equilibrium exists.

\section{Mechanism design}

As the ranking of the buyer surplus is ambiguous, the question arises whether there are other mechanisms that dominate first- and second-price auctions. This section analyzes mechanisms to maximize buyer surplus. We limit ourselves to cases that are relevant for procurement. That is, cases in which it is optimal to procure with probability one. ${ }^{18}$ We begin our analysis by deriving an optimal mechanism under full commitment. This mechanism serves as a benchmark. We provide a condition for the project value $R$ such that procuring with probability one is optimal under full commitment. We then turn our attention to mechanism design without commitment and provide conditions for $R$ such that the full commitment allocation can be implemented even without commitment. ${ }^{19}$ Finally, we show that in those cases buyer surplus without commitment equals the surplus in an optimal mechanism under full commitment.

Optimal mechanism with full commitment. Our model combines aspects of auction design and sequential screening and thus leads to similar results. The following lemma provides a condition for $R$ such that it is optimal to procure the good with probability one and characterizes an optimal mechanism.

Lemma 4. There is an $R^{c}$ such that whenever $R \geq R^{c}$ the buyer-surplus maximizing mechanism implements the efficient allocation:

(i) Select the most efficient supplier in period one.

(ii) Continue production in period two with probability one.

\footnotetext{
${ }^{18}$ See the introduction for a discussion of this assumption. A complete characterization of the optimal mechanism under limited commitment lies beyond the scope of this manuscript. There are several technical hurdles rendering the problem intractable, see for instance Laffont and Tirole (1990), Bester and Strausz (2001) and Pollrich (2017).

${ }^{19}$ Note that if $R$ is small, implementing the full-commitment outcome is impossible. To see this recall that the optimal mechanism features "no-distortion-at-the-top". That is, the buyer procures from the low-cost type with probability one in each period, irrespective of the cost realization in period 2. Without commitment and $R$ small the buyer optimally sets a non-trivial reservation price in period 2 even if she is certain to face the low-cost type.
} 
The buyer surplus is then maximized with a second-price auction and appropriately designed binary bid space $\left\{b_{l}, b_{h}\right\}$.

Proof. The proof uses standard techniques from static and sequential screening. We relegate it to Appendix A.

Independent of the size of $R$, an optimal mechanism selects the most efficient supplier in period one. If this supplier has low costs, production continues in period two irrespective of second-period costs. ${ }^{20}$ The mechanisms extracts all (information) rents from second-period production already in period one. If the contract supplier has high costs, the mechanism induces a cut-off $r \in\left[\underline{c}_{h}, \bar{c}_{h}\right]$ for second-period production. Depending on $R$, this cut-off is determined by trading off second-period efficiency with information rents to low-cost suppliers. If a low-cost supplier claims high costs and is still selected as a contract supplier, he gains additional information rents from facing a more favorable cost-distribution than high-cost suppliers. However, when the buyer's valuation $R$ is sufficiently large, shut-down in period two becomes sub-optimal.

Implementation without commitment. Without commitment, the terms of trade have to be sequentially optimal. Contrary to the full commitment case, neither the second-period payments nor the production decision can be specified in period one. As outlined earlier, it is without loss of generality to consider posted price mechanisms in the second period. The supplier continues production only if his payment exceeds his costs. Nevertheless, the buyer is tempted to reduce the price to increase surplus even if this is not optimal from the point of view of period one. This trade-off crucially depends on the buyer's belief about production costs and the project value $R$. The following lemma establishes conditions on $R$ such that the allocation from Lemma 4 can be implemented even without commitment.

Lemma 5. There are finite values $R^{=}$and $R^{\neq}$such that

- when $\bar{c}_{l}=\bar{c}_{h}$ the efficient allocation is implementable if $R>R^{=}$,

- when $\bar{c}_{l}<\bar{c}_{h}$ the efficient allocation is implementable if $R>R^{\neq}$.

Proof. The proof can be found in Appendix A.

We first discuss the case $\bar{c}_{l}=\bar{c}_{h}$. Consider a second-price auction where the buyer observes the winner's payment but not his bid. In a separating equilibrium there are two distinct beliefs on the equilibrium path. When the contract supplier's payment is low, the buyer beliefs she is facing a low-type. When the contract supplier's payment

\footnotetext{
${ }^{20}$ This is the well-known no-distortion-at-the-top result or, in procurement, no-distortion-at-thebottom.
} 
is high, the buyer holds an interior belief $\mu_{2}$. In the first case, offering the payment $\bar{c}_{l}$ is optimal whenever $R-\bar{c}_{l} \geq F_{l}(c)(R-c)$ for all $c \in\left[\underline{c}_{l}, \bar{c}_{l}\right] . R^{=}$is the lowest value for $R$ such that the latter condition is satisfied. ${ }^{21}$ But then Assumption 1 implies that the buyer optimally offers a payment equal to $\bar{c}_{l}=\bar{c}_{h}$ following any belief about the contract supplier's type she may hold.

Matters are more complicated with $\bar{c}_{l}<\bar{c}_{h}$. Consider again a separating equilibrium of a second-price auction. For the belief $\mu_{2}=1$ (the buyer is certain to face a low-cost supplier) a similar condition on $R$ as before yields continued production. However, this condition does not ensure that no shutdown is optimal following any other belief. To see this, suppose the buyer is almost certain to face a low-cost supplier. She is almost certain to never face a supplier with a second-period cost exceeding $\bar{c}_{l}$. Thus, it is optimal to shut down production for suppliers with costs in the interval $\left(\bar{c}_{l}, \bar{c}_{h}\right]$. In such a case, belief management becomes important. It is crucial for the buyer to induce a belief such that she is willing to offer $\bar{c}_{h}$ in period two and thus implement the full-commitment allocation. A regular second-price auction may not achieve this, since it makes the buyer too optimistic even when the resulting price is high. ${ }^{22}$

However, the full-commitment allocation is still implementable. Consider an $\alpha$ second-price auction. The $\alpha$-second-price auction has the same payment rule as the second-price auction. It reveals with probability $\alpha$ whether the winner's bid has been lower than his payment and thus manages the belief updating of the buyer. If the winner's payment is high and the winner's bid is not revealed, the buyer becomes less optimistic about the contract supplier's type. Our discussion of first-price auctions reveals that too much information revelation is in conflict with an efficient allocation in period one. Condition $R>R^{\neq}$guarantees that separation of types in period one and appropriate belief management are possible.

Optimal mechanism without commitment. Lemma 4 and Lemma 5 are key to our final proposition. For large values of $R$ we have established two results. First, the optimal mechanism under full commitment implements the efficient allocation. Second, this allocation is implementable under limited commitment. The following proposition shows that for large values of $R$ buyer-surplus coincides when using an $\alpha$-second-price auction with appropriate binary bid space $\left\{b_{l}, b_{h}\right\} .{ }^{23}$

Proposition 8. The following holds true.

\footnotetext{
${ }^{21}$ Formally, $R^{=}=\sup _{\underline{c}_{l} \leq c \leq \bar{c}_{l}} \frac{\bar{c}_{l}-c F_{l}(c)}{1-F_{l}(c)}$. See also the proof of Lemma 5 for why $R^{=}<\infty$.

${ }^{22}$ The updated belief in the second price auction is $n \mu_{1} /\left(n \mu_{1}+1-\mu_{1}\right)$ which converges to one as $n$ grows large.

${ }^{23}$ See the proof of Proposition 8 for the specific bids our mechanism uses.
} 
(i) If $\bar{c}_{l}=\bar{c}_{h}$ and $R>\max \left\{R^{c}, R^{=}\right\}$, a second price auction with appropriate bid space $\left\{b_{l}, b_{h}\right\}$ yields the same buyer surplus as an optimal mechanism under full commitment and thus maximizes buyer surplus under limited commitment.

(ii) If $\bar{c}_{l}<\bar{c}_{h}$ and $R>\max \left\{R^{c}, R^{\neq}\right\}$, an $\alpha$-second-price auction with appropriate bid space $\left\{b_{l}, b_{h}\right\}$ yields the same buyer surplus as an optimal mechanism under full commitment and thus maximizes buyer surplus under limited commitment.

\section{Experiment}

In a laboratory experiment, we investigate the influence of the procurement mechanism on bidding behavior. We test whether the lack of commitment indeed leads to pooling in the first-price auction and thus reduces efficiency and buyer surplus.

\subsection{Design and protocol}

In our experimental setting, one buyer faces two potential suppliers. As we focus on suppliers' bidding behavior, the role of the buyer is computerized. The buyer awards one main contract and a follow-up contract, which can only be completed by the contract supplier. Both contracts are of equal size. Suppliers are either low-cost or high-cost both with a probability of one half. Low-cost suppliers produce at a cost of zero ECU in both periods. High-cost suppliers produce at a cost of 11 ECU in both periods.

We compare three procurement mechanisms. A first-price sealed-bid auction with renegotiation (FPA2), a second-price sealed-bid auction (SPA2) with renegotiation, and a first-price sealed-bid auction without renegotiation (FPA1). In all three auctions, suppliers can select bids from the discrete bid grid $\{0$ ECU, 6 ECU, 11 ECU $\}$. Subjects only specify their bid for the case that they are low-cost, i.e., have costs of 0 ECU, high-cost suppliers automatically place a bid equal to their costs of 11 ECU. ${ }^{24}$

In the FPA2 and the SPA2 treatment, after the price of the initial auction was announced, the contract supplier receives an automated offer for the follow-up contract. We instruct the subjects that the buyer will offer the lowest price for which she can be certain that it is accepted by the contract supplier. The offer is thus automatically accepted by the contract supplier. ${ }^{25}$ In the FPA1 treatment, there is no renegotiation and the price for the main contract is also applied to the follow-up contract.

\footnotetext{
${ }^{24}$ This is a consequence of limited liability and prevents subjects from accumulating losses. Bidding below 11 ECU is dominated for high-cost suppliers.

${ }^{25}$ Each price below 11 ECU necessarily reveals that the costs of the contract supplier are zero.
} 
Each of the three treatments included six independent cohorts. Each cohort had 8 human participants all in the role of suppliers, who were randomly rematched in 33 procurement interactions including 3 practice periods. Each laboratory session was conducted with two cohorts (16 people) in the laboratory simultaneously. In total 144 human subjects participated in our auction experiments.

Each participant was randomly assigned to one of the three treatments. The experimental sessions were conducted in the Cologne Laboratory for Economic Research at the University of Cologne and the Mannheim Laboratory for Economic Research at the University of Mannheim. Participants were recruited using the online recruitment system ORSEE (Greiner, 2015) and earning money was the only incentive offered. The experimental interface was programmed using oTree (Chen et al., 2016).

Upon arrival at the laboratory, the participants were seated at computer terminals. They were handed written instructions and they read these on their own. When all participants had finished reading, they had the opportunity to ask clarifying questions that were answered in private. To ensure a common understanding of the game all participants had to solve a quiz consisting of control questions. ${ }^{26}$ At the beginning of each period, the eight participants in one cohort were divided into four groups consisting of two suppliers and one computerized buyer. In order to rule out super game effects, we randomly determined one of the 30 periods to be payoff relevant at the end of the experiment. Each period consisted of ten subperiods for which the bidding strategy and matching were fixed. In each of the subperiods suppliers' costs were randomly determined and one main contract and one follow-up contract were awarded. $^{27}$

We computed cash earnings for each participant by multiplying the total earnings from all subperiods of the payoff-relevant period by a pre-determined exchange rate and adding it to a 5 Euro participation fee. Participants were paid their earnings in private and cash at the end of the session. Sessions lasted approximately 60 minutes and subjects participating in the auctions earned an average of 14.54 Euro.

\subsection{Hypotheses}

The theory in Section 3 predicts that the FPA2 mechanism results in inefficient supplier selection and high prices. The SPA2 solves the problem by information management, namely by concealing the contract supplier's bid to the buyer. In the FPA1

\footnotetext{
${ }^{26}$ We invited 22 to 24 participants per session and only the first 16 participants that answered all control questions correctly participated in the experimental sessions. Those participants that did not qualify for the experiment received 5 Euro for their participation.

${ }^{27}$ Fixing the bidding strategy for several subperiods reduces the payoff variance given a bidding strategy, but still avoids super game effects, which might arise if multiple periods are payoff relevant.
} 


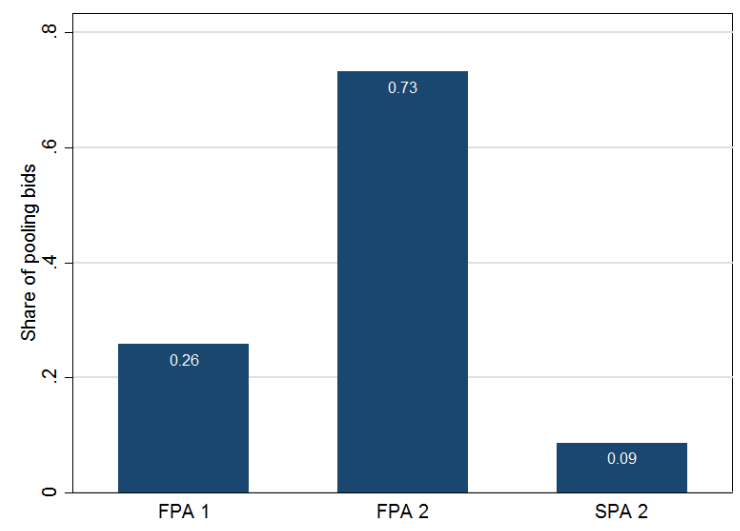

Figure 1: Comparison of the procurement mechanisms in terms of efficiency. Illustrated is how frequently low-cost suppliers place pooling bids in the different procurement mechanisms.

we test the value of commitment. We derive the following testable hypotheses for our experiment.

Hypothesis 1. The FPA2 is less efficient than the FPA1.

Hypothesis 2. The FPA2 is less efficient than the SPA2.

Hypothesis 3. The FPA1 is as efficient as the SPA2.

Hypothesis 4. The FPA2 generates less buyer surplus than the FPA1.

Hypothesis 5. The FPA2 generates less buyer surplus than the SPA2.

Hypothesis 6. The SPA2 generates less buyer surplus than the FPA1.

\subsection{Results}

Throughout this section, we report the $p$-values based on the non-parametric WilcoxonMann-Whitney test comparing the different procurement mechanisms taking each cohort as one independent observation. The tested hypothesis is that the respective distributions do not differ between the procurement mechanisms.

We start the analysis of the experimental results by comparing the level of efficiency in the different procurement mechanisms. To do so, we consider the share of pooling bids, that is, the share of high bids placed by low-cost suppliers. The pooling behavior is illustrated in Figure 1. As predicted, the FPA2 results in substantial pooling. In contrast, other procurement mechanisms yield significantly more efficient outcomes. The SPA2 is significantly more efficient than the FPA1.

Result 1. The FPA2 is less efficient than the FPA1 ( $p=0.0039)$. 


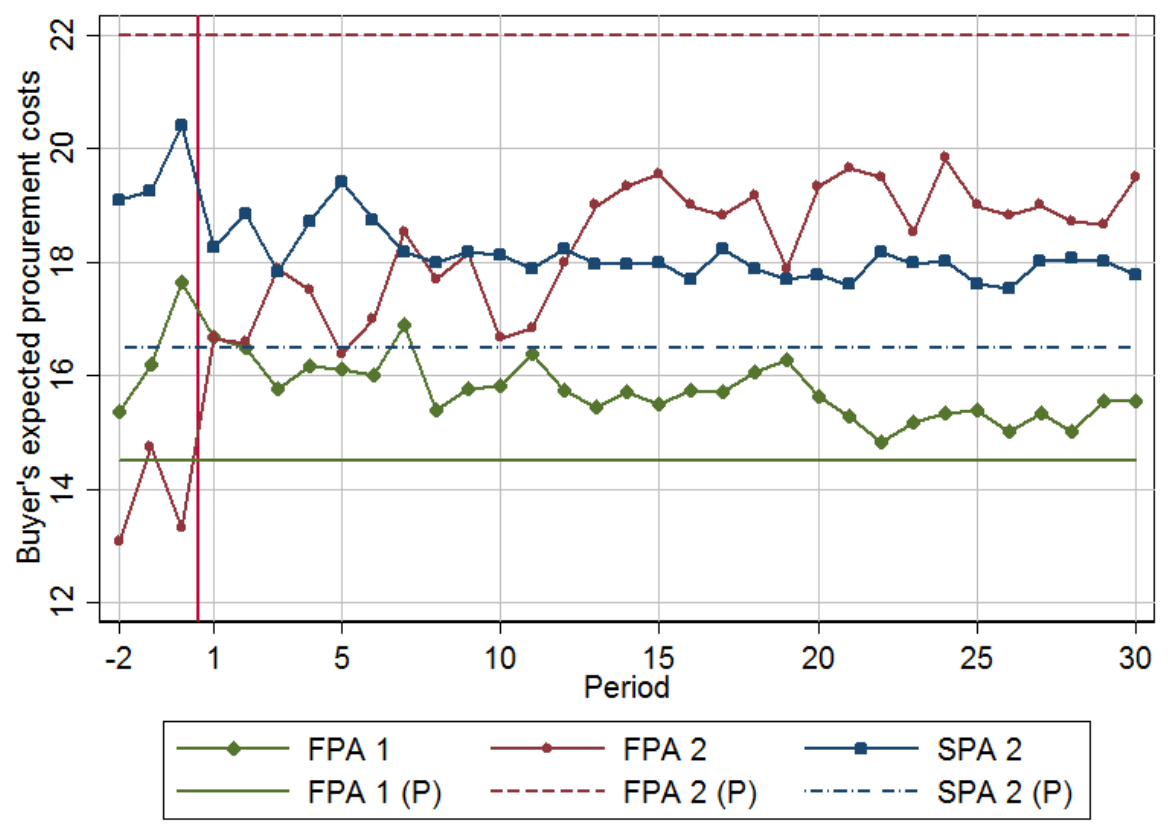

Figure 2: Evolution of buyer's expenses over time. Illustrated is the (expected) total cost of a buyer awarding the main contract and the follow-up contract. Observations left from the vertical line refer to the practice periods. Lines without marker display equilibrium predictions.

Result 2. The FPA2 is less efficient than the SPA2 $(p=0.0039)$.

Result 3. The FPA1 is less efficient than the SPA2 $(p=0.0039)$.

As trade is guaranteed to occur, we can compare buyer surplus by considering buyer expenses. We compare the buyer expenses by calculating the expected expenses given the suppliers' bidding strategies and the actual matching. We consider the buyer's expected expenses and not the realized expenses to minimize noise due to randomness. Figure 2 illustrates the evolution of the buyer's expenses over time.

Result 4. The FPA2 generates less buyer surplus than the FPA1 ( $p=0.0039)$.

Result 5. The FPA2 generates the same buyer surplus as the SPA2 $(p=0.7488)$.

Result 6. The SPA2 generates less buyer surplus than the FPA1 ( $p=0.0039)$.

In terms of buyer surplus, the FPA1 dominates the other procurement mechanisms, which is in line with theory. The comparison of the FPA2 with the SPA2 shows that the difference in expenses is not significant if we consider all 30 periods. Subjects in FPA2 learn to pool over time. Whenever the subjects do not pool on the highest bid, the first-price auctions generate more buyer surplus than the SPA2. This is a 
consequence of the bid-grid, as any undercutting of the high-cost types decreases the price by at least 5 ECU. Figure 2 suggests that the FPA2 achieves better results than the SPA2 only if suppliers are inexperienced. If suppliers are experienced, the SPA2 results in higher buyer surplus than the FPA2.

Our data includes 48 individual participants bidding in six independent cohorts in each of the three procurement mechanisms, each individual bids in 30 auctions. We take advantage of this panel structure to obtain better estimates of the dynamics of bidding behavior. We fit the following two regression models

$$
\begin{aligned}
\text { Model 1: } K_{i, t}=\beta_{0} & +\beta_{F P A 1} \times F P A 1+\beta_{S P A 2} \times S P A 2 \\
& +\nu_{i}+\epsilon_{i, t} \\
\text { Model 2: } K_{i, t}=\beta_{0} & +\beta_{F P A 1} \times F P A 1+\beta_{S P A 2} \times S P A 2 \\
& +\beta_{t} \times(t-30)+\beta_{t, F P A 1} \times(t-30)+\beta_{t, S P A 2} \times(t-30) \\
+ & +\nu_{i}+\epsilon_{i, t}
\end{aligned}
$$

In both models, FPA1 and SPA2 are dummy variables indicating the treatment. Hence, the FPA2 treatment serves as the baseline. In Model 2, $t$ is the period number (1 to 30$)$. By using $t-30$ we set the last period as the baseline period.

Note that there are two error components in the models: one that is independent across all observations $\epsilon_{i, t}$ and one that is cohort-specific $\nu_{i}$. Each error term has a mean of zero and some positive standard deviation. In this, we use the random effects model to control for cohort heterogeneity.

We interpret the coefficients in Model 1 as follows: $\beta_{0}$ reflects the buyer's expenses in the FPA2, $\beta_{F P A 1}$ and $\beta_{S P A 2}$ express how much higher the buyer's expenses are in the FPA1 and SPA2 treatments, respectively, compared to the FPA2 treatment. The interpretation of these coefficients is the same in Model 2, the only difference being that in model 1 they reflect average expenses and in model 2 they reflect expenses at the end of the experiment, i.e. for auctions with experienced suppliers. Furthermore, in Model $2 \beta_{t}$ estimates how the learning of suppliers affects the buyer's expenses over time in the FPA2. The coefficients $\beta_{t, F P A 1}$ and $\beta_{t, S P A 2}$ express in how far this learning effect in the other procurement mechanisms is different from the learning effect in the FPA2.

The estimates for the models are presented in Table 1 . Model 1 states that the buyer's expenses in the FPA2 are on average 18.37 ECU, which is not significantly different from her expenses in the SPA2. In contrast to that, the expenses are significantly lower in the FPA1. Both findings confirm the observations reported in Result 4 and Result 5, respectively. Model 2 tells us that the buyer's expenses in the FPA2 
Table 1: Regressions of buyer expenses.

\begin{tabular}{lcc}
\hline \hline & \multicolumn{2}{c}{ Model } \\
& $18.37^{* * *}$ & $19.63^{* * *}$ \\
& $(0.548)$ & $(0.780)$ \\
$\beta_{0}$ & $-2.647^{* * *}$ & $-4.477^{* * *}$ \\
$\beta_{F P A 1}$ & $(0.606)$ & $(0.885)$ \\
& -0.290 & $-1.937^{*}$ \\
$\beta_{S P A 2}$ & $(0.564)$ & $(0.793)$ \\
& & $0.0864^{* *}$ \\
$\beta_{t}$ & & $(0.0295)$ \\
& & $-0.126^{* * *}$ \\
$\beta_{t, F P A 1}$ & & $(0.0322)$ \\
& & $-0.114^{* * *}$ \\
$\beta_{t, S P A 2}$ & & $(0.0316)$ \\
\hline Observations & 540 & 540 \\
\hline \hline Robust standard errors in parentheses \\
$* p<0.05,{ }^{* *} p<0.01,{ }^{* * *} p$ & $<0.001$
\end{tabular}

are 19.63 ECU at the end of the experiment. For experienced suppliers both the FPA1 and the SPA2 yield significantly lower expenses than the FPA2. Furthermore, it shows that the buyer's expenses become larger over time in the FPA2 and that the differences between the expenses in the FPA2 and the SPA2 or FPA1 increase over time.

Result 7. The FPA2 generates lower buyer surplus than the SPA2 if suppliers are experienced ( $p=0.015$, Table 1$)$.

The analysis of the experimental data shows that bidding behavior is broadly in line with the theoretical predictions. This means, for each procurement mechanism the equilibrium bid is the most frequent bid and its frequency becomes larger over time. At the same time, we observe substantial deviations from the equilibrium bidding strategy especially in the SPA2, which in turn makes the SPA2 more expensive for the buyer than predicted. In Appendix B we shed more light on this using a quantal response analysis. 


\section{$7 \quad$ Discussion of model extensions}

In this section, we discuss extensions of the model and the robustness of our results. We will focus on the equilibria and the buyer-surplus ranking in first-price and secondprice auctions.

\subsection{Bargaining power in the second period}

We assumed that in the second period the buyer has all the bargaining power. With this assumption in mind, suppliers are particularly cautious about revealing information to ensure information rents in the second period. If the contract supplier had all the bargaining power in period two, information release would not be an issue.

There are many ways to model bargaining under asymmetric information. To keep the model tractable, we consider a simple reduced-form model of intermediate bargaining power. Suppose that in the second period the contract supplier can make a take-it-or-leave-it offer to the buyer with probability $\gamma$. With probability $1-\gamma$ the buyer makes a take-it-or-leave-it offer to the contract supplier. The parameter $\gamma$ measures bargaining power. The case $\gamma=0$ corresponds to our main model.

We start the analysis by considering the second period. If the buyer makes the offer, the analysis from Section 3 remains unchanged. If the supplier makes the offer he always demands a payment equal to $Q \cdot R$ and production continues with certainty. From the point of view of the first period, the expected second-period profit of a winning supplier at price $p$ (and induced belief $\mu_{2}(p)$ ) is

$$
Q \cdot\left(\gamma \cdot\left(R-E_{\theta}[c]\right)+(1-\gamma) \cdot \pi_{2}\left(c_{\theta}, \mu_{2}(p)\right)\right)
$$

The equilibrium of the second-price auction remains qualitatively the same. Suppliers place a bid such that their expected profit is zero if they win the auction and receive a payment equal to their bid. That is, a type $\theta$ bidder submits the bid

$$
b_{\theta}=c_{\theta}-Q \cdot\left[\gamma \cdot\left(R-E_{\theta}[c]\right)+(1-\gamma) \cdot \pi_{2}\left(c_{\theta}, \mu_{2}(p)\right)\right]
$$

with $\mu_{2}(p)$ as defined in Proposition 1.

Next, consider pooling equilibria in the first-price auction. Parallel to Proposition 2 
a pooling equilibrium exists whenever there is a $b$ such that

$$
\begin{aligned}
b \leq & \left.c_{l}-Q \cdot\left[\gamma \cdot\left(R-E_{l}[c]\right)+(1-\gamma) \cdot \pi_{2}\left(c_{l}, \mu_{1}\right)\right)\right] \\
& +\frac{n}{n-1} \cdot Q \cdot(1-\gamma) \cdot\left(\pi_{2}\left(c_{l}, \mu_{1}\right)-\pi_{2}\left(c_{l}, 1\right)\right), \\
b \leq & c_{h}-Q \cdot\left[\gamma \cdot\left(R-E_{h}[c]\right)+(1-\gamma) \cdot \pi_{2}\left(c_{h}, \mu_{1}\right)\right] \\
& +\frac{n}{n-1} \cdot Q \cdot(1-\gamma) \cdot\left(\pi_{2}\left(c_{h}, \mu_{1}\right)-\pi_{2}\left(c_{h}, 1\right)\right), \\
b \geq & c_{h}-Q \cdot\left[\gamma \cdot\left(R-E_{h}[c]\right)+(1-\gamma) \cdot \pi_{2}\left(c_{h}, \mu_{1}\right)\right] .
\end{aligned}
$$

As $\gamma \cdot Q \cdot\left(R-E_{l}[c]\right)>\gamma \cdot Q \cdot\left(R-E_{h}[c]\right)$ a pooling equilibrium is harder to sustain the higher the bargaining power of the suppliers. Comparing the first condition and the third condition yields a similar result as Corollary 1. That is, if condition (5) is satisfied and $\gamma<1$, a pooling equilibrium exists whenever $Q$ is sufficiently large. Note that (5) is independent of the bargaining power $\gamma$. Bargaining power merely influences the critical threshold $Q_{\text {pool }}$. A similar but reverse logic applies to separating equilibria. These are easier to sustain if the suppliers' bargaining power increases.

Overall, the ranking of the buyer surplus from Section 4 remains intact. Buyer surplus is higher in the second-price auction than in the pooling equilibrium of the first-price auction but lower than in the separating equilibrium of the first-price auction. For small values of $Q$ the separating equilibrium exists and thus the first-price auction has an equilibrium with higher buyer surplus. The critical threshold of $Q$ increases in the suppliers' bargaining power. If condition (5) holds true and $Q$ is sufficiently large, all equilibria of the first-price auction yield lower buyer surplus as compared to the second-price auction.

\subsection{Arbitrary type space $\Theta$}

Suppose that a supplier's cost of fulfilling a contract in period one is $c_{\theta}$ with $\theta \in \Theta=$ $[\underline{\theta}, \bar{\theta}]$. The types of the suppliers are independently and identically distributed with a distribution function $G$. Denote by $\mathbf{I}_{\theta}$ the degenerated belief with mass one on $\theta$. That is, the buyer believes she is facing a supplier of type $\theta$ with certainty. ${ }^{28}$

First, observe that the equilibrium of the second price auction remains qualitatively the same. Bidders bid such that their expected profit is 0 if they win the auction with a price equal to their bid. That is, each bidder bids $c_{\theta}-Q \cdot \pi_{2}\left(c_{\theta}, \mu_{2}\left(c_{\theta}\right)\right)$ with $\mu_{2}\left(c_{\theta}\right)$ denoting the updated belief of the buyer after observing that $c_{\theta}$ is the second lowest bid.

\footnotetext{
${ }^{28}$ Our results hold for continuous and discrete type spaces. Thus, the distribution can exhibit mass points and gaps.
} 
Second, observe that a pooling equilibrium in the first-price auction still exists under similar conditions as before. With the same argument as in Proposition 2, a pooling equilibrium in the first-price auction exists whenever there is a $b$ such that

$$
\begin{aligned}
& b \leq c_{\theta}-Q \cdot \pi_{2}\left(c_{\theta}, G\right)+\frac{n}{n-1} \cdot Q \cdot\left(\pi_{2}\left(c_{\theta}, G\right)-\pi_{2}\left(c_{\theta}, \mathbf{I}_{\underline{\theta}}\right)\right) \\
& b \geq c_{\bar{\theta}}-Q \cdot \pi_{2}\left(c_{\bar{\theta}}, G\right)
\end{aligned}
$$

for all $\theta \in \Theta$. Similar to condition (5) in Corollary 1, whenever

$$
\pi_{2}\left(c_{\theta}, G\right)-\pi_{2}\left(c_{\bar{\theta}}, G\right)>n \cdot\left(\pi_{2}\left(c_{\theta}, \mathbf{I}_{\underline{\theta}}\right)-\pi_{2}\left(c_{\bar{\theta}}, G\right)\right)
$$

for all $\theta \in \Theta$ a pooling equilibrium exists if $Q$ is sufficiently large.

To see that condition (18) can be satisfied, consider the case of persistent types: the left-hand side is strictly positive, while the right-hand side is strictly negative. Consequently, condition (18) is always satisfied in a model with persistent types and a pooling equilibrium exists when $Q$ is sufficiently large.

Third, we show that a separating equilibrium of the first-price auction fails to exist. We illustrate the argument for the case of persistent types. That is, the case where second-period cost $c$ is equal to first-period cost $c_{\theta}$ for all bidders and cost types. We provide an argument for discrete types and for continuous types.

Discrete types. Suppose that a separating equilibrium exists. With persistent types it holds that $\pi_{2}\left(c_{\theta}, \mathbf{I}_{\theta}\right)=0$ for all $\theta$, and $\pi_{2}\left(c_{\underline{\theta}}, \mathbf{I}_{\theta}\right)>0$ for all $\theta>\underline{\theta}$. Now consider the lowest type $\underline{\theta}$ and the second-lowest type $\hat{\theta}$. With similar arguments as in Proposition 5 the equilibrium is monotonic and the support of the bids is connected. That is, the supremum of the bid support of type $\underline{\theta}$ is equal to the infimum of the bid support of type $\hat{\theta}$. Denote this value by $b$. If there is no mass point at $b$, type $\underline{\theta}$ gains by bidding slightly above $b$. The winning probability changes only marginally whereas the second period payoff increases discontinuously from 0 to $\pi_{2}\left(c_{\underline{\theta}}, \mathbf{I}_{\hat{\theta}}\right)>0$. If there is a mass point at $b$, type $\hat{\theta}$ strictly gains by undercutting $b .^{29}$ The winning probability increases discontinuously whereas second-period profits stay 0 . It follows, that bidding on disjoint intervals is not an equilibrium. Thus, a separating equilibrium does not exist.

With two persistent types there is a unique separating equilibrium. This equilibrium is sustained as the high-cost type places a zero-profit bid with probability one. Thus, he has no profitable downward deviation. This provides an incentive for

\footnotetext{
${ }^{29}$ In equilibrium, the profit of type $\hat{\theta}$ when bidding $b$ is strictly positive. Otherwise, he could deviate to the bid of type $\bar{\theta}$.
} 
the low-cost type to separate from the pool. As argued above, with more than two types, such a mass point is impossible in a separating equilibrium for types below the highest-cost type. Thus, lower-cost types would like to deviate from a separating strategy and mimic higher-cost types.

Continuous types. Suppose a separating pure-strategy equilibrium exists. As before, the equilibrium is monotonic. That is, there exists a decreasing bidding function $\beta\left(c_{\theta}\right)$. The payoff of a bidder with type $\theta$ from deviating and bidding some $b=\beta\left(c_{\hat{\theta}}\right)$ can be written as

$$
\left(1-G\left(\beta\left(c_{\hat{\theta}}\right)\right)^{n-1} \cdot\left(\beta\left(c_{\hat{\theta}}\right)-c_{\theta}+Q \cdot \pi_{2}\left(c, \mathbf{I}_{\hat{\theta}}\right)\right) .\right.
$$

With persistent types, for $c_{\hat{\theta}} \leq c_{\theta}$ we have $\pi_{2}\left(c_{\theta}, \mathbf{I}_{\theta}\right)=0$, and for $c_{\hat{\theta}}>c_{\theta}$ we have $\pi_{2}\left(c_{\theta}, \mathbf{I}_{\hat{\theta}}\right)=c_{\hat{\theta}}-c_{\theta}$. Thus, the left derivative of the profit function is

$$
-(n-1) \cdot\left(1-G\left(c_{\hat{\theta}}\right)\right)^{n-2} \cdot g\left(c_{\hat{\theta}}\right) \cdot\left(\beta\left(c_{\hat{\theta}}\right)-c_{\theta}\right)+\left(1-G\left(c_{\hat{\theta}}\right)\right)^{n-1} \cdot \beta^{\prime}\left(c_{\hat{\theta}}\right) .
$$

The right derivative is

$$
\begin{array}{r}
-(n-1) \cdot\left(1-G\left(c_{\hat{\theta}}\right)\right)^{n-2} \cdot g\left(c_{\hat{\theta}}\right) \cdot\left(\beta\left(c_{\hat{\theta}}\right)-c_{\theta}\right. \\
\left.+Q \cdot\left(c_{\hat{\theta}}-c_{\theta}\right)\right)+\left(1-G\left(c_{\hat{\theta}}\right)\right)^{n-1} \cdot\left(\beta^{\prime}\left(c_{\hat{\theta}}\right)+Q\right) .
\end{array}
$$

The necessary condition for $\beta$ to be an equilibrium bidding function is that at $c_{\theta}=$ $c_{\hat{\theta}}$ either the left derivative is zero and the right derivative is negative or the right derivative is zero and the left derivative is positive. Now, if expression (19) is equal to zero, expression (20) is equal to $Q \cdot\left(1-G\left(c_{\hat{\theta}}\right)\right)^{n-1}$ which is positive. If expression (20) is equal to zero, it follows that

$$
-(n-1) \cdot\left(1-G\left(c_{\hat{\theta}}\right)\right)^{n-2} \cdot g\left(c_{\hat{\theta}}\right) \cdot\left(\beta\left(c_{\hat{\theta}}\right)-c_{\theta}\right)+\left(1-G\left(c_{\hat{\theta}}\right)\right)^{n-1} \cdot \beta^{\prime}\left(c_{\hat{\theta}}\right)=-Q \cdot\left(1-G\left(c_{\hat{\theta}}\right)\right)^{n-1} .
$$

Thus, the left derivative is negative and $\beta$ does not fulfill the necessary condition for equilibrium. Thus, a separating equilibrium does not exist.

The result is intuitive. With persistent types, in a potential separating equilibrium, all bidders earn a profit of zero in the second period. Thus, the optimal bidding function in period one would be the classical equilibrium of the first-price auction. However, in such an equilibrium the bidders would like to deviate and mimic highcost types to earn second-period profits. If the bid is chosen in a way that deviation upwards is not profitable, bidders have a deviation incentive downward as they still do not earn second-period profits and would prefer to bid like in a standard single-round 
first-price auction. ${ }^{30}$ Summing up, if we extend the model beyond the two-types case, the main conclusions remain intact. First, the second price auction is well behaved, achieves an efficient allocation in period one and reasonable buyer-surplus. Second, the first-price auction in this setting performs poorly. Either $Q$ is sufficiently large and all types pool on the same bid. In this case, the first-price auction is highly inefficient and provides a strictly lower buyer surplus then the second-price auction. Or $Q$ is small and a pure-strategy equilibrium fails to exist. Thus, with a lack of commitment and future interaction first-price auctions should be used with caution.

\section{Literature Review}

Procurement auctions are inherently different from sales auctions. For example, in procurement the auctioneer cares about whether the winning bidder is qualified to deliver the good (Fugger et al., 2016; Wan and Beil, 2009), is concerned with supplier investments (Beer et al., 2017; Li and Wan, 2016; Li, 2013), might want to diversify the supply base by procuring the same good from two or more suppliers (Chaturvedi et al., 2014), or has to employ an agent to verify quality who is prone to corruption (Burguet, 2017; Gretschko and Wambach, 2016). The feature at the heart of this manuscript is that, as compared to sales, procurement often results in long-term relationships. As a consequence, renegotiation of the original terms of the contract is a major concern. A classic strand of the literature investigates moral hazard as the main source of renegotiation (Fudenberg and Tirole, 1990 or Herweg and Schmidt, 2015 for a more recent contribution). Another line of reasoning identifies design flaws as a source of renegotiation (Herweg and Schmidt, 2017; Herweg and Schwarz, 2018). Suppliers have private information about potential design flaws of the procurement project and leverage this information to capture additional rents during the project. We extend the literature on renegotiation in procurement by considering renegotiation in an adverse selection setting. Suppliers reveal private information during the initial procurement auction which in turn the buyer exploits in the renegotiation.

The problem at hand is related to the literature on sales without commitment. The literature started with considering monopolists selling a durable good to a single buyer (e.g., Bulow (1982), Hart and Tirole (1988)) and developed into auctions without commitment. A seller designs an auction but cannot commit to retaining the object when the auction does not allocate it (e.g., when the reserve price is not met). Skreta (2015) analyzes optimal selling mechanisms with a finite horizon. If the good was not allocated in the first stage, the seller proposes a new mechanism. She shows

\footnotetext{
${ }^{30}$ The result also extends to partial pooling equilibria, as the argument remains valid also if the bid function is monotonic only for a subset of types.
} 
that optimal mechanisms resemble their static counterparts. Liu et al. (2019) study a similar problem but with an infinite horizon. They show that with sufficiently many bidders a version of the Coase conjecture applies and an efficient auction is uniquely optimal. Vartiainen (2013) goes one step further by studying a seller who does not adhere to the mechanism initially proposed irrespective of whether the good was to be sold or not. He proves that the English auction is an optimal mechanism, as it reveals just the right amount of information and the seller does not wish to propose an alternative mechanism.

Most of these models consider negative selection: renegotiation only takes place if the good is not sold. In this case, remaining bidders have low valuations (bad types). As a consequence, a ratchet effect kicks in as in the classical literature on the Coase conjecture. ${ }^{31}$ Tirole (2016) demonstrates for the single-agent case that positive selection leads to fundamentally different results. With positive selection, at the stage of renegotiation, only good types are left. He shows, that in this case lack of commitment is not an issue. We also study a model with positive selection. Renegotiation only takes place if a supplier was chosen. This always renders the buyer more optimistic about the supplier's type. Thus, our results differ markedly from the results in the auction without commitment literature. For example, we derive sufficient conditions such that the full-commitment outcome is implementable.

Apart from auctions, there is also a growing literature on mechanism design with limited commitment. Bester and Strausz (2001), Bester and Strausz (2007) and Pollrich (2017) study the problem of a principal who contracts with a privately informed agent. The principal can commit to some decisions, but some other decisions remain at his discretion. As in our model, the agent takes into account the information conveyed in her communication with the principal, in particular, its effect on the principal's subsequent decisions. Bester and Strausz (2001) show a version of the revelation principle when communication is bound to be one-shot. ${ }^{32}$ In a similar setting, Bester and Strausz (2007) highlight the profitability of indirect communication protocols over the use of one-shot communication. Pollrich (2017) studies a specific setting where the principal can audit the agent after executing the contract, but cannot contractually commit to audit frequencies. He shows that optimal contracts involve communication via an impartial mediator, who correlates the agent's (revealed) information with the principal decision to audit. The general insight is that it is beneficial to obscure some of the information generated by the mechanism. In an auction framework, some pricing rules like the second-price rule achieve this in a natural way. However, standard pricing rules fail to do so optimally.

\footnotetext{
${ }^{31}$ See Liu et al. (2019) and the references therein for a comprehensive overview.

${ }^{32}$ Their result does not extend to the case with multiple agents, see Bester and Strausz (2000).
} 
Our model exhibits some similarities with models of sequential auctions, auctions with resale and mechanism design with aftermarkets. In all cases, information release influences subsequent play. However, the mechanism designer herself does not directly care about the released information. In particular, she can design arbitrary information regimes and even conceal the winner and/or the price in stage one. This is not possible in our model. As delivery has to take place in period one the buyer necessarily observes the allocation and the transfer.

The literature on sequential auctions focuses mainly on three informational regimes in first-price auctions: all bids disclosed, winning bid disclosed, no bids disclosed. Bergemann and Hörner (2018) investigate a model of infinitely repeated first-price auctions among bidders with binary and persistent types. When either all bids or only the winner's bid are disclosed, equilibrium multiplicity obtains. As in our results, they find pooling, separating and semi-separating equilibria. Also, comparative statics are similar: pooling equilibria exist when the future becomes sufficiently important (measured in terms of the discount factor in their model) or the number of bidders is sufficiently large. However, they do not compare different auction formats and disclosure regimes. Thomas (2010) studies a setting where two suppliers compete for two procurement projects in sequential first-price auctions. He employs a setting with binary and persistent types. Crucially, both projects are of equal size, eliminating the possibility for pooling. Auction revenues are highest when no information on bids and prices is revealed, a regime that is inherently ruled out in our model. Cason et al. (2011) investigate sequential first-price auctions experimentally. In a setting with binary and persistent types, they find that with low competition disclosing all bids is better than disclosing only the winning bid. With high competition, the ranking reverses.

In the literature on auctions with aftermarkets, all bidders interact with each other after the auction with payoffs depending on all bidders' types. Information revealed during the auction affects the aftermarket interaction and thereby indirectly bidding behavior. Haile (2003) studies an auction with symmetric bidders, where the winner has the opportunity to resell the item to one of the losing bidders. He compares different auction formats and shows that revenue equivalence may fail, due to differences in information leakage of the auction formats. ${ }^{33}$ Goeree (2003) studies a situation in which bidders bid in first-price, second-price, or English auctions for a competitive advantage in an aftermarket game. In his model, bidders profit from overstating their value. Thus, they try to signal their value through high bids. Separating equilibria exist in all considered auction formats and revenue is highest in the English auction.

\footnotetext{
${ }^{33}$ Auctions with resale are also studied in, e.g., Zheng (2002); Garratt and Tröger (2006); Hafalir and Krishna (2008), and Carroll and Segal (ming).
} 
In our model, bidders benefit from understating their value. This makes our analysis different. The revenue ranking can be reversed and separating equilibria may fail to exist.

In the last strand of literature, instead of interacting with losing bidders, the winning bidder interacts with a third party in the aftermarket. The mechanism designer affects the aftermarket interaction by revealing information about the winner. Calzolari and Pavan (2006a) study a monopolist who sells to a buyer with a binary valuation. The buyer can then resell the good to a third party. Revenue maximizing mechanisms involve randomization and non-trivial information disclosure beyond the fact whether the good is sold. In their model aftermarket interaction is beneficial for the seller as she can extract revenues from resale. In our case, future interaction can hurt the mechanism designer. Calzolari and Pavan (2006b) study information release when a sequence of principals contract with the same agent. They provide sufficient conditions for the optimality of agent privacy along the hierarchy. Agent privacy is not an option in our model as the future interaction is with the original mechanism designer. Dworczak (2017) analyzes information disclosure in mechanism design with abstract aftermarkets (not limited to resale). He provides conditions under which optimal information release is limited to the minimal information: no information beyond the fact that the good was allocated is released.

\section{References}

Beer, R., H.-S. Ahn, and S. Leider (2017). Can trustworthiness in a supply chain be signaled? Management Science 64(9), 3974-3994.

Bergemann, D. and J. Hörner (2018). Should first-price auctions be transparent? American Economic Journal: Microeconomics 10(3), 177-218.

Bester, H. and R. Strausz (2000). Imperfect commitment and the revelation principle: the multi-agent case. Economics Letters 69(2), 165-171.

Bester, H. and R. Strausz (2001). Contracting with imperfect commitment and the revelation principle: The single agent case. Econometrica 69(4), 1077-1098.

Bester, H. and R. Strausz (2007). Contracting with imperfect commitment and noisy communication. Journal of Economic Theory 136(1), 236-259.

Brandt, F. (2010). Auctions. In B. Rosenberg (Ed.), Handbook of Financial Cryptography and Security, Chapter 2, pp. 49-58. Boca Raton, FLA: CRC Press. 
Bulow, J. I. (1982). Durable-goods monopolists. Journal of political Economy 90(2), $314-332$.

Burguet, R. (1996). Optimal repeated purchases when sellers are learning about costs. Journal of Economic Theory 68(2), 440-455.

Burguet, R. (2017). Procurement design with corruption. American Economic Journal: Microeconomics 9(2), 315-341.

Calzolari, G. and A. Pavan (2006a). Monopoly with resale. RAND Journal of Economics 37(2), 362-375.

Calzolari, G. and A. Pavan (2006b). On the optimality of privacy in sequential contracting. Journal of Economic Theory 130, 168-204.

Carroll, G. and I. Segal (forthcoming). Robustly optimal auctions with unknown resale opportunities. Review of Economics Studies.

Cason, T. N., K. N. Kannan, and R. Siebert (2011). An experimental study of information revelation policies in sequential auctions. Management Science 57(4), 667-688.

Chaturvedi, A., D. R. Beil, and V. Martínez-de Albéniz (2014). Split-award auctions for supplier retention. Management Science 60(7), 1719-1737.

Chen, D. L., M. Schonger, and C. Wickens (2016). otree-an open-source platform for laboratory, online, and field experiments. Journal of Behavioral and Experimental Finance 9, 88-97.

Davis, A., E. Katok, and A. Kwasnica (2014). Should sellers prefer auctions? A laboratory comparison of auctions and sequential mechanisms. Management Science 60, $2666-2683$.

Davis, a. M., E. Katok, and a. M. Kwasnica (2010). Do Auctioneers Pick Optimal Reserve Prices? Management Science 57(1), 177-192.

Dworczak, P. (2017). Mechanism design with aftermarkets: Cutoff mechanisms.

Fudenberg, D. and J. Tirole (1990). Moral hazard and renegotiation in agency contracts. Econometrica 58(6), 1279-1319.

Fugger, N., E. Katok, and A. Wambach (2016). Collusion in dynamic buyerdetermined reverse auctions. Management Science 62, 518-533. 
Garratt, R. and T. Tröger (2006). Speculation in standard auctions with resale. Econometrica $74(3), 753-769$.

Goeree, J. K. (2003). Bidding for the future: Signaling in auctions with an aftermarket. Journal of Economic Theory 108(2), 345-364.

Greiner, B. (2015). Subject pool recruitment procedures: organizing experiments with orsee. Journal of the Economic Science Association 1(1), 114-125.

Gretschko, V. and A. Wambach (2016). Procurement under public scrutiny: auctions versus negotiations. RAND Journal of Economics $47(4)$.

Hafalir, I. and V. Krishna (2008). Asymmetric auctions with resale. American Economic Review 98(1), 87-112.

Haile, P. A. (2003). Auctions with private uncertainty and resale opportunities. Journal of Economic Theory 108(1), 72-110.

Hart, O. and J. Tirole (1988). Contract renegotiation and Coasian dynamics. Review of Economic Studies 55(4), 509-540.

Herweg, F. and K. M. Schmidt (2015). Loss aversion and inefficient renegotiation. Review of Economic Studies 82(1), 297-332.

Herweg, F. and K. M. Schmidt (2017). Auctions versus negotiations: the effects of inefficient renegotiation. RAND Journal of Economics 48(3), 647-672.

Herweg, F. and M. A. Schwarz (2018). Optimal cost overruns: Procurement auctions with renegotiation. International Economic Review 49(56).

Laffont, J.-J. and J. Tirole (1990). Adverse selection and renegotiation in procurement. Review of Economic Studies 57(4), 597-625.

Li, C. (2013). Sourcing for supplier effort and competition: Design of the supply base and pricing mechanism. Management Science 59(6), 1389-1406.

Li, C. and Z. Wan (2016). Supplier competition and cost improvement. Management Science 63(8), 2460-2477.

Liu, Q., K. Mierendorff, X. Shi, and W. Zhong (2019). Auctions with limited commitment. American Economic Review 109(3), 876-910.

McKelvey, R. D. and T. R. Palfrey (1995). Quantal response equilibria for normal form games. Games and Economic Behavior 10(1), 6-38. 
Mueller, F., K. O. Stahl, and F. Wachtler (2016). Upstream relationships in the automotive industry: A contractual perspective. mimeo, 1-30.

Myerson, R. (1981). Optimal auction design. Mathematics of operations research 6(1), $58-73$.

Pollrich, M. (2017). Mediated audits. RAND Journal of Economics 48(1), 44-68.

Riley, J. G. (1979). Informational equilibrium. Econometrica 47(2), 331-359.

Skreta, V. (2015). Optimal auction design under non-commitment. Journal of Economic Theory 159, 854-890.

Thomas, C. J. (2010). Information revelation and buyer profits in repeated procurement competition. Journal of Industrial Economics 58(1), 79-105.

Tirole, J. (2016). From bottom of the barrel to cream of the crop: Sequential screening with positive selection. Econometrica 84(4), 1291-1343.

Vartiainen, H. (2013). Auction design without commitment. Journal of the European Economic Association 11(2), 316-342.

Wan, Z. and D. R. Beil (2009). RFQ auctions with supplier qualification screening. Operations Research 57(4), 934-949.

Zheng, C. Z. (2002). Optimal auction with resale. Econometrica 70(6), 2197-2224.

\section{A Proofs}

\section{A.1 Proofs of Section 3}

\section{Proof of Lemma 2.}

First observe that

$$
\frac{\mu_{2} \cdot F_{l}(c)+\left(1-\mu_{2}\right) \cdot F_{h}(c)}{\mu_{2} \cdot f_{l}(c)+\left(1-\mu_{2}\right) \cdot f_{h}(c)}
$$

is increasing in $\mu_{2}$. Differentiating with respect to $\mu_{2}$ gives (we omit the argument $c$ )

$$
\begin{aligned}
& \frac{\mu_{2} \cdot\left(f_{l}-f_{h}\right) \cdot\left(F_{l}-F_{h}\right)+f_{h} \cdot\left(F_{l}-F_{h}\right)-F_{h} \cdot\left(f_{l}-f_{h}\right)-\mu_{2} \cdot\left(f_{l}-f_{h}\right) \cdot\left(F_{l}-F_{h}\right)}{\left(\mu_{2} \cdot f_{l}+\left(1-\mu_{2}\right) \cdot f_{h}\right)^{2}} \\
= & \frac{f_{h} \cdot F_{l}-F_{h} \cdot f_{l}}{\left(\mu_{2} \cdot f_{l}+\left(1-\mu_{2}\right) \cdot f_{h}\right)^{2}}>0,
\end{aligned}
$$

where the last equality follows from Assumption 1. 
Now assume $\mu_{2}, \mu_{2}^{\prime} \in[0,1]$ with $\mu_{2}<\mu_{2}^{\prime}$. Clearly, if $P\left(\mu_{2}\right)=\bar{c}_{h}$ we have $P\left(\mu_{2}\right) \geq$ $P\left(\mu_{2}^{\prime}\right)$. Hence, assume $P\left(\mu_{2}\right)<\bar{c}_{h}$. First-order stochastic dominance implies

$$
\begin{aligned}
R-\bar{c}_{h} & <\left(R-P\left(\mu_{2}\right)\right) \cdot\left(\mu_{2} \cdot F_{l}\left(P\left(\mu_{2}\right)\right)+\left(1-\mu_{2}\right) \cdot F_{h}\left(P\left(\mu_{2}\right)\right)\right) \\
& \leq\left(R-P\left(\mu_{2}\right)\right) \cdot\left(\mu_{2}^{\prime} \cdot F_{l}\left(P\left(\mu_{2}\right)\right)+\left(1-\mu_{2}^{\prime}\right) \cdot F_{h}\left(P\left(\mu_{2}\right)\right)\right) .
\end{aligned}
$$

So $P\left(\mu_{2}^{\prime}\right)<\bar{c}_{h}$. Both $P\left(\mu_{2}\right)$ and $P\left(\mu_{2}^{\prime}\right)$ are determined by the first-order condition (1). Using our initial observation and the first-order condition for $P\left(\mu_{2}\right)$ we have for all $P>P\left(\mu_{2}\right)$

$$
\begin{aligned}
R-P<R-P\left(\mu_{2}\right) & =\frac{\mu_{2} \cdot F_{l}\left(P\left(\mu_{2}\right)\right)+\left(1-\mu_{2}\right) \cdot F_{h}\left(P\left(\mu_{2}\right)\right)}{\mu_{2} \cdot f_{l}\left(P\left(\mu_{2}\right)\right)+\left(1-\mu_{2}\right) \cdot f_{h}\left(P\left(\mu_{2}\right)\right)} \\
& \leq \frac{\mu_{2}^{\prime} \cdot F_{l}\left(P\left(\mu_{2}\right)\right)+\left(1-\mu_{2}^{\prime}\right) \cdot F_{h}\left(P\left(\mu_{2}\right)\right)}{\mu_{2}^{\prime} \cdot f_{l}\left(P\left(\mu_{2}\right)\right)+\left(1-\mu_{2}^{\prime}\right) \cdot f_{h}\left(P\left(\mu_{2}\right)\right)} \\
& \leq \frac{\mu_{2}^{\prime} \cdot F_{l}(P)+\left(1-\mu_{2}^{\prime}\right) \cdot F_{h}(P)}{\mu_{2}^{\prime} \cdot f_{l}(P)+\left(1-\mu_{2}^{\prime}\right) \cdot f_{h}(P)},
\end{aligned}
$$

where the last inequality follows from Assumption 1. Consequently, we must have $P\left(\mu_{2}^{\prime}\right) \leq P\left(\mu_{2}\right)$, which proves the first claim. Finally, observe that for all $\mu_{2}<\mu_{2}^{\prime}$

$$
\pi_{2}\left(c_{\theta}, \mu_{2}\right)=\mathbb{E}_{\theta}\left[\left(P\left(\mu_{2}\right)-c\right)^{+}\right] \leq \mathbb{E}_{\theta}\left[\left(P\left(\mu_{2}^{\prime}\right)-c\right)^{+}\right]=\pi_{2}\left(c_{\theta}, \mu_{2}^{\prime}\right) .
$$

\section{Proof of Proposition 1.}

We start the proof by arguing that the proposed behavior indeed constitutes an equilibrium. In the second part, we will establish that this equilibrium is the unique symmetric Bayes-Nash equilibrium. For both parts, observe, that off-path beliefs of the principal are irrelevant for the bidders incentives. ${ }^{34}$ If a deviating bidder wins the auction, the price will be set by one of the other bidders and thus the buyer's updated belief comes from the set of on-path beliefs. If a deviating bidder loses the auction, he will not participate in the second period. Thus, the off-path beliefs of the buyer are irrelevant, even if a bidder thinks of placing an off-path bid.

In the second stage, it is always optimal for suppliers to accept the offers if these are weakly larger than their costs.

By Lemma 1 the second-period offers of the buyer are the optimal mechanism given her belief. The beliefs are calculated by using Bayes rule given the strategy of the suppliers in period 1 and the observed price.

A high-cost supplier with cost $c_{h}$ expects a profit of zero from his bid given the

\footnotetext{
${ }^{34}$ We say a price $p$ is on path if $p \in \operatorname{supp}\left(\mathcal{B}_{h}\right)$ or $p \in \operatorname{supp}\left(\mathcal{B}_{l}\right)$. The belief of the principal formed after observing a price on path is called an on-path belief.
} 
strategy of the buyer. All smaller bids above the bid of a low-cost supplier $b_{l}$ yield also a profit of 0 . Any bid equal or below the bid of a low-cost supplier $b_{l}$ yields a strictly negative expected profit by Lemma 2. Bidding above his equilibrium bid does not improve the supplier's expected profit, because such bids are never accepted given the strategy of his competitors.

Now consider a low-cost supplier with cost $c_{l}$. Bidding $b>b_{l}$ yields the same expected profit as the equilibrium bid if $p>b$ or if $p<b_{l}$. In the case that the first-period price is $b>p \geq b_{l}$, bidding $b$ yields a pay-off of 0 . Thus, the equilibrium bid yields a strictly higher expected profit.

Bidding $b<b_{l}$ yields the same profit as in equilibrium if the first-period price is $p \geq b_{l}$ or if $p<b$. If the first-period price is $b \leq p<b_{l}$, she makes a negative expected profit. Thus, bidding below the equilibrium bis is weakly dominated by the equilibrium bid.

We turn our attention to proving that the proposed equilibrium is the unique symmetric equilibrium. We proceed in three steps. First, we will show that the lowcost type places lower bids in equilibrium than the high-cost type. That is, every equilibrium is weakly monotonic. It follows directly that the on-path belief of the buyer is weakly decreasing in the prices. That is, a lower observed price leads to a weakly higher probability of facing the low-cost type. Second, we will use this to demonstrate that every equilibrium is in pure strategies. Third, we show that any equilibrium bid $b_{\theta}$ yields an expected pay-off of zero to the bidder if $p=b_{\theta}$.

In what follows we will denote by $\operatorname{Prob}(b)$ the probability of winning with bid $b$ in a previously selected equilibrium. Denote by $G(p)=1-\operatorname{Prob}(p)$ as the distribution of the lowest of the other bidders' bids (i.e. the price) in equilibrium. Let $\underline{p}=\min \left\{\underline{b}_{l}, \underline{b}_{h}\right\}$ and $\bar{p}=\max \left\{\bar{b}_{l}, \bar{b}_{h}\right\}$ denote the infinum and supremum of the support of $G$.

Step 1: $\bar{b}_{l} \leq \underline{b}_{h}$. That is, the low-cost type places lower bids than the high-cost type.

Proof. Suppose otherwise. In this case, there exists bids $b^{\prime}>b^{\prime \prime}$ with $\operatorname{Prob}\left(b^{\prime \prime}\right)>$ $\operatorname{Prob}\left(b^{\prime}\right)$ such that

$$
\begin{aligned}
\operatorname{Prob}\left(b^{\prime \prime}\right) \cdot\left(\mathbb{E}\left[p \mid p \geq b^{\prime \prime}\right]-c_{h}+\mathbb{E}\left[Q \cdot \pi_{2}\left(c_{l}, \mu_{2}(p)\right) \mid p \geq b^{\prime \prime}\right]\right) \geq \\
\operatorname{Prob}\left(b^{\prime}\right) \cdot\left(\mathbb{E}\left[p \mid p \geq b^{\prime}\right]-c_{h}+\mathbb{E}\left[Q \cdot \pi_{2}\left(c_{l}, \mu_{2}(p)\right) \mid p \geq b^{\prime}\right]\right)
\end{aligned}
$$

and

$$
\begin{aligned}
\operatorname{Prob}\left(b^{\prime}\right) \cdot\left(\mathbb{E}\left[p \mid p \geq b^{\prime}\right]-c_{l}+\mathbb{E}\left[Q \cdot \pi_{2}\left(c_{h}, \mu_{2}(p)\right) \mid p \geq b^{\prime}\right]\right) \geq \\
\operatorname{Prob}\left(b^{\prime \prime}\right) \cdot\left(\mathbb{E}\left[p \mid p \geq b^{\prime \prime}\right]-c_{l}+\mathbb{E}\left[Q \cdot \pi_{2}\left(c_{h}, \mu_{2}(p)\right) \mid p \geq b^{\prime \prime}\right]\right) .
\end{aligned}
$$


Subtracting both inequalities gives

$$
\begin{gathered}
\operatorname{Prob}\left(b^{\prime}\right) \cdot\left(\bar{c}-\underline{c}+\mathbb{E}\left[Q \cdot \pi_{2}\left(c_{l}, \mu_{2}(p)\right) \mid p \geq b^{\prime}\right]-\mathbb{E}\left[Q \cdot \pi_{2}\left(c_{h}, \mu_{2}(p)\right) \mid p \geq b^{\prime}\right]\right) \geq \\
\operatorname{Prob}\left(b^{\prime \prime}\right) \cdot\left(\bar{c}-\underline{c}+\mathbb{E}\left[Q \cdot \pi_{2}\left(c_{l}, \mu_{2}(p)\right) \mid p \geq b^{\prime \prime}\right]-\mathbb{E}\left[Q \cdot \pi_{2}\left(c_{h}, \mu_{2}(p)\right) \mid p \geq b^{\prime \prime}\right]\right) .
\end{gathered}
$$

Thus, for a contradiction we will show that

$$
\begin{aligned}
& \operatorname{Prob}\left(b^{\prime}\right) \cdot \mathbb{E}\left[\pi_{2}\left(c_{l}, \mu_{2}(p)\right) \mid p \geq b^{\prime}\right]-\operatorname{Prob}\left(b^{\prime}\right) \cdot \mathbb{E}\left[\pi_{2}\left(c_{h}, \mu_{2}(p)\right) \mid p \geq b^{\prime}\right] \\
& \quad \leq \operatorname{Prob}\left(b^{\prime \prime}\right) \cdot \mathbb{E}\left[\pi_{2}\left(c_{l}, \mu_{2}(p)\right) \mid p \geq b^{\prime \prime}\right]-\operatorname{Prob}\left(b^{\prime \prime}\right) \cdot \mathbb{E}\left[\pi_{2}\left(c_{h}, \mu_{2}(p)\right) \mid p \geq b^{\prime \prime}\right] .
\end{aligned}
$$

It follows

$$
\begin{aligned}
\int_{b^{\prime}}^{\bar{p}} \pi_{2}\left(c_{l}, \mu_{2}(p)\right) d G(p)-\int_{b^{\prime}}^{\bar{p}} & \pi_{2}\left(c_{h}, \mu_{2}(p)\right) d G(p) \\
& \leq \int_{b^{\prime \prime}}^{\bar{p}} \pi_{2}\left(c_{l}, \mu_{2}(p)\right) d G(p)-\int_{b^{\prime \prime}}^{\bar{p}} \pi_{2}\left(c_{h}, \mu_{2}(p)\right) d G(p) .
\end{aligned}
$$

This is equivalent to

$$
0 \leq \int_{b^{\prime \prime}}^{b^{\prime}} \pi_{2}\left(c_{l}, \mu_{2}(p)\right) d G(p)-\int_{b^{\prime \prime}}^{b^{\prime}} \pi_{2}\left(c_{h}, \mu_{2}(p)\right) d G(p)
$$

This is obviously a true statement as $\pi_{2}\left(c_{l}, \mu_{2}(p)\right) \geq \pi_{2}\left(c_{h}, \mu_{2}(p)\right)$ for all $p \in[\underline{p}, \bar{p}]$.

We have shown that in any equilibrium the low-cost type places lower bids than the high-cost type. It follows directly that in any equilibrium and for any pair of on-path prices $p^{\prime}$ and $p^{\prime \prime}$ with $p^{\prime} \leq p^{\prime \prime}$ it follows that $\mu_{2}\left(p^{\prime}\right) \geq \mu_{2}\left(p^{\prime \prime}\right)$.

Step 2: In any symmetric equilibrium all bidders play pure strategies.

Proof. Suppose otherwise. In this case, there exist $b^{\prime}>b^{\prime \prime}$ with $\operatorname{Prob}\left(b^{\prime \prime}\right)>\operatorname{Prob}\left(b^{\prime}\right)$ such that

$$
\begin{aligned}
\operatorname{Prob}\left(b^{\prime \prime}\right) \cdot\left(\mathbb{E}\left[p \mid p \geq b^{\prime \prime}\right]-c_{\theta}+\mathbb{E}\left[Q \cdot \pi_{2}\left(c_{\theta}, \mu_{2}(p)\right) \mid p \geq b^{\prime \prime}\right]\right)= \\
\operatorname{Prob}\left(b^{\prime}\right) \cdot\left(\mathbb{E}\left[p \mid p \geq b^{\prime}\right]-c_{\theta}+\mathbb{E}\left[Q \cdot \pi_{2}\left(c_{\theta}, \mu_{2}(p)\right) \mid p \geq b^{\prime}\right]\right) .
\end{aligned}
$$

This is equivalent to

$$
0=\int_{b^{\prime \prime}}^{b^{\prime}} p d G(p)-c_{\theta} \cdot\left(P\left(b^{\prime \prime}\right)-\operatorname{Prob}\left(b^{\prime}\right)\right)+\int_{b^{\prime \prime}}^{b^{\prime}} Q \cdot \pi_{2}\left(c_{\theta}, \mu_{2}(p)\right) d G(p) .
$$

Observe that due to $\operatorname{Prob}\left(b^{\prime \prime}\right)>\operatorname{Prob}\left(b^{\prime}\right), \int_{b^{\prime \prime}}^{b^{\prime}} p d G(p)$ is strictly larger than $\int_{b^{\prime \prime}}^{b^{\prime}} b^{\prime \prime} d G(p)$. 
Moreover, due to the monotonic on-path belief of the principal and Lemma 2,

$$
\int_{b^{\prime \prime}}^{b^{\prime}} Q \cdot \pi_{2}\left(c_{\theta}, \mu_{2}(p)\right) d G(p) \geq \int_{b^{\prime \prime}}^{b^{\prime}} Q \cdot \pi_{2}\left(c_{\theta}, \mu_{2}\left(b^{\prime \prime}\right)\right) d G(p) .
$$

Thus,

$$
\int_{b^{\prime \prime}}^{b^{\prime}} p d G(p)-c_{\theta} \cdot\left(\operatorname{Prob}\left(b^{\prime \prime}\right)-\operatorname{Prob}\left(b^{\prime}\right)\right)+\int_{b^{\prime \prime}}^{b^{\prime}} Q \cdot \pi_{2}\left(c_{\theta}, \mu_{2}(p)\right) d G(p)
$$

is strictly larger than

$$
\int_{b^{\prime \prime}}^{b^{\prime}} b^{\prime \prime} d G(p)-c_{\theta} \cdot\left(\operatorname{Prob}\left(b^{\prime \prime}\right)-\operatorname{Prob}\left(b^{\prime}\right)\right)+\int_{b^{\prime \prime}}^{b^{\prime}} Q \cdot \pi_{2}\left(c_{\theta}, \mu_{2}\left(b^{\prime \prime}\right)\right) d G(p) .
$$

This is equivalent to

$$
\left(b^{\prime \prime}-c_{\theta}+Q \cdot \pi_{2}\left(c_{\theta}, \mu_{2}\left(b^{\prime \prime}\right)\right)\right) \cdot\left(\operatorname{Prob}\left(b^{\prime \prime}\right)-\operatorname{Prob}\left(b^{\prime}\right)\right) .
$$

$b^{\prime \prime}-c_{\theta}+Q \cdot \pi_{2}\left(c_{\theta}, \mu_{2}\left(b^{\prime \prime}\right)\right)$ is the profit from winning at a price of $b^{\prime \prime}$. Thus, this expression has to be larger or equal to 0 otherwise it would be a profitable deviation to bid slightly above $b^{\prime \prime}$. It follows that

$$
0<\int_{b^{\prime \prime}}^{b^{\prime}} p d G(p)-c_{\theta}\left(\operatorname{Prob}\left(b^{\prime \prime}\right)-\operatorname{Prob}\left(b^{\prime}\right)\right)+\int_{b^{\prime \prime}}^{b^{\prime}} Q \cdot \pi_{2}\left(c_{\theta}, \mu_{2}(p)\right) d G(p),
$$

a contradiction.

Step 3: Any equilibrium bid $b_{\theta}$ yields an expected pay-off of zero to the bidder if $p=b_{\theta}$.

Proof. We present the argument for the low-cost type $c_{l}$. The argument for the highcost type works in the same way. Suppose that the equilibrium bid $b_{l}$ is such that $b_{l}-c_{l}+Q \cdot \pi_{2}\left(c_{l}, \mu_{2}\left(b_{l}\right)\right)>0$. In any monotonic, pure-strategy equilibrium, whenever a bidder with the low-cost type faces at least another bidder with a low-cost type his probability of winning is strictly below 1 , as he ties with this bidder. However, if he bids below $b_{l}$ he will never tie with other bidders and win the project with probability 1 without revealing any additional information to the buyer as the price will be set by one of the other bidders. As $b_{l}-c_{l}+Q \cdot \pi_{2}\left(c_{l}, \mu_{2}\left(b_{l}\right)\right)>0$ this is a strictly profitable deviation and thus a contradiction.

Combining step 2 and 3 yields the result that the proposed equilibrium is the unique symmetric equilibrium. 


\section{Proof of Proposition 2.}

Observe that pooling is an equilibrium whenever we set the off-path beliefs of the principal to $\mu_{2}(p)=1$ if $p \neq b$ and for both types, $c_{l}$ and $c_{h}$ the pay-off from pooling is larger than the payoff from undercutting $b$ by an arbitrarily small amount. The payoff from pooling is

$$
\frac{1}{n}\left(b-c_{\theta}+Q \cdot \pi_{2}\left(c_{\theta}, \mu_{1}\right)\right) .
$$

The payoff from undercutting is

$$
b-c_{\theta}+Q \cdot \pi_{2}\left(c_{\theta}, 1\right)
$$

Thus, pooling is more beneficial than undercutting whenever

$$
\left.(n-1) \cdot c_{\theta} \geq(n-1) \cdot b+n \cdot Q \cdot \pi_{2}\left(c_{\theta}, 1\right)\right)-Q \cdot \pi_{2}\left(c_{\theta}, \mu_{1}\right) .
$$

The lower bound for $b$ is determined by setting the expected pay-off of the high-cost type to zero. This shows that conditions (2), (3) and (4) are necessary and sufficient for a pooling equilibrium to exist.

\section{Proof of Proposition 3.}

To prove the claim, we first show that the low-cost type $c_{l}$ is indifferent between all bids in $\left[\underline{b}_{l}, b\right)$. Second, we demonstrate that $\mathcal{B}_{l}(\widetilde{b})$ is a distribution. Third, we show that conditions (6), (7) and (8) ensure that the low-cost type does not want to deviate to $b$ and the high-cost type does not want to undercut $b$. To see that the low-cost type $c_{l}$ is indifferent between all bids in $\left[\underline{b}_{l}, b\right)$ consider the pay-off of a low-cost type from bidding some $\widetilde{b} \in\left[\underline{b}_{l}, b\right)$ given that the other bidders play the proposed strategy:

$$
\left(1-\mu_{1}+\mu_{1} \cdot\left(1-\mathcal{B}_{l}(\widetilde{b})\right)\right)^{n-1} \cdot\left(\widetilde{b}+\pi_{2}\left(c_{l}, 1\right)-c_{l}\right)
$$

substituting $\mathcal{B}_{l}(\widetilde{b})$ from $(8)$ and rearranging yields:

$$
\underline{b}_{l}+Q \cdot \pi_{2}\left(c_{l}, 1\right)-c_{l}
$$

As the last expression is independent of $b$, the low-cost type is indifferent between all bids in $b \in\left[\underline{b}_{l}, b\right)$. We now demonstrate that $\mathcal{B}_{l}(\widetilde{b})$ is a distribution. It is easy to see that $\mathcal{B}_{l}(\widetilde{b})$ is increasing in $\widetilde{b}$. Thus, it remains to show that $\mathcal{B}_{l}(b)=1$ and $\mathcal{B}_{l}\left(\underline{b}_{l}\right)=0$. 
Observe that substituting $\underline{b}_{l}$ from expression (10) into (9) yields

$$
\mathcal{B}_{l}(b)=1-\left(\frac{\left(1-\mu_{1}\right)^{n-1} \cdot\left(b+Q \cdot \pi_{2}\left(c_{l}, 1\right)-c_{l}\right)}{\mu_{1}^{n-1}\left(b+Q \cdot \pi_{2}\left(c_{l}, 1\right)-c_{l}\right)}\right)^{\frac{1}{n-1}}+\frac{1-\mu_{1}}{\mu_{1}} .
$$

Hence,

$$
\mathcal{B}_{l}(b)=1-\left(\frac{\left(1-\mu_{1}\right)^{n-1}}{\mu_{1}^{n-1}}\right)^{\frac{1}{n-1}}+\frac{1-\mu_{1}}{\mu_{1}}=1
$$

Moreover,

$$
\begin{aligned}
\mathcal{B}_{l}\left(\underline{b}_{l}\right)=1-\left(\frac{\underline{b}_{l}+Q \cdot \pi_{2}\left(c_{l}, 1\right)-c_{l}}{\mu_{1}^{n-1}\left(\underline{b}_{l}+Q \cdot \pi_{2}\left(c_{l}, 1\right)-c_{l}\right)}\right)^{\frac{1}{n-1}} & +\frac{1-\mu_{1}}{\mu_{1}} \\
& =1-\left(\frac{1}{\mu_{1}^{n-1}}\right)^{\frac{1}{n-1}}+\frac{1-\mu_{1}}{\mu_{1}}=0 .
\end{aligned}
$$

Bidding strictly below $\underline{b}_{l}$ is not a profitable deviation. The winning probability does not increase but the profit in case of winning decreases. Bidding above $b$ yield an expected profit of 0 and is therefore not a profitable deviation. Thus, it remains to show that the low-cost type does not want to deviate to $b$ and the high-cost type does not want to undercut $b$.

The payoff from bidding $b$ is

$$
\left(1-\mu_{1}\right)^{n-1} \cdot \frac{1}{n} \cdot\left(b-c_{\theta}+Q \cdot \pi_{2}\left(c_{\theta}, 0\right)\right)
$$

The payoff from undercutting is

$$
\left(1-\mu_{1}\right)^{n-1} \cdot\left(b-c_{\theta}+Q \cdot \pi_{2}\left(c_{\theta}, 1\right)\right)
$$

Thus, bidding $b$ is more beneficial than undercutting whenever

$$
\left.(n-1) \cdot c_{\theta} \geq(n-1) \cdot b+n \cdot Q \cdot \pi_{2}\left(c_{\theta}, 1\right)\right)-Q \cdot \pi_{2}\left(c_{\theta}, 0\right) .
$$

This shows that conditions (6), (7) and (8) are necessary and sufficient for a separating equilibrium to exist.

\section{Proof of Proposition 4.}

To prove the claim, we first show that the low-cost type $c_{l}$ is indifferent between all bids in $\left[\underline{b}_{l}, b\right)$. Second, we show that conditions (12), (13) and (14) ensure that the low-cost type is indifferent between a bid in $\left[\underline{b}_{l}, b\right)$ and $b$ and the high-cost type does not want to undercut $b$. Third, we demonstrate that $\mathcal{B}_{l}(\widetilde{b})$ is a distribution. Fourth, 
we show that whenever there is no separating or full pooling equilibrium in the firstprice auction, there exists a $\mu$ and a $b$ such that conditions (12), (13) and (14) are fulfilled.

To see that the low-cost type $c_{l}$ is indifferent between all bids in $\left[\underline{b}_{l}, b\right)$ consider the pay-off of a low-cost type from bidding some $\widetilde{b} \in\left[\underline{b}_{l}, b\right)$ given that the other bidders play the proposed strategy:

$$
\left(1-\mu_{1}+\mu_{1} \cdot p_{\mu}+\mu_{1} \cdot\left(1-p_{\mu}\right) \cdot\left(1-\mathcal{B}_{l}(\widetilde{b})\right)\right)^{n-1} \cdot\left(\widetilde{b}+\pi_{2}\left(c_{l}, 1\right)-c_{l}\right)
$$

substituting $\mathcal{B}_{l}(\widetilde{b})$ from $(15)$ and rearanging yields:

$$
\underline{b}_{l}+Q \cdot \pi_{2}\left(c_{l}, 1\right)-c_{l} .
$$

As the last expression is independent of $b$, the low-cost type is indifferent between all bids in $b \in\left[\underline{b}_{l}, b\right)$.

Bidding strictly below $\underline{b}_{l}$ is not a profitable deviation. The winning probability does not increase but the profit in case of winning decreases. Bidding above $b$ yields an expected profit of 0 and is therefore not a profitable deviation. Thus, it remains to show that the low-cost type is indifferent between bidding in $\left[\underline{b}_{l}, b\right)$ and $b$ and that the high-cost type does not want to undercut $b$. The payoff from bidding $b$ is

$$
\left(1-\mu_{1}+p \cdot \mu_{1}\right)^{n-1} \cdot \frac{1}{n} \cdot\left(b-c_{\theta}+Q \cdot \pi_{2}\left(c_{\theta}, \mu\right)\right) .
$$

The payoff from slightly undercutting is

$$
\left(1-\mu_{1}+p \cdot \mu_{1}\right)^{n-1} \cdot\left(b-c_{\theta}+Q \cdot \pi_{2}\left(c_{\theta}, 1\right)\right)
$$

Thus, bidding $b$ is more beneficial than undercutting whenever

$$
(n-1) \cdot c_{\theta}>(n-1) \cdot b+n \cdot Q \cdot \pi_{2}\left(c_{\theta}, 1\right)-Q \cdot \pi_{2}\left(c_{\theta}, \mu\right) .
$$

A bidder is indifferent between bidding $b$ and undercutting whenever

$$
(n-1) \cdot c_{\theta}=(n-1) \cdot b+n \cdot Q \cdot \pi_{2}\left(c_{\theta}, 1\right)-Q \cdot \pi_{2}\left(c_{\theta}, \mu\right) .
$$

Thus, condition (12) ensures that the low-cost type is indifferent and condition (13) ensures that the high-cost type does not want to deviate to a lower bid.

We now demonstrate that $\mathcal{B}_{l}(\widetilde{b})$ is a distribution. It is easy to see that $\mathcal{B}_{l}(b)$ is increasing in $b$. Thus, it remains to show that $\mathcal{B}_{l}(b)=1$ and $\mathcal{B}_{l}\left(\underline{b}_{l}\right)=0$. Observe that 
substituting $\underline{b}_{l}$ from expression (16) into (15) yields

$$
\mathcal{B}_{l}(b)=1-\left(\frac{\left(1-\mu_{1}+p_{\mu} \cdot \mu_{1}\right)^{n-1}\left(b+Q \cdot \pi_{2}\left(c_{l}, 1\right)-c_{l}\right)}{\left(1-p_{\mu}\right)^{n-1} \cdot \mu_{1}^{n-1} \cdot\left(b+Q \cdot \pi_{2}\left(c_{l}, 1\right)-c_{l}\right)}\right)^{\frac{1}{n-1}}+\frac{1-\mu_{1}+p_{\mu} \cdot \mu_{1}}{\left(1-p_{\mu}\right) \cdot \mu_{1}} .
$$

Hence,

$$
\mathcal{B}_{l}(b)=1-\left(\frac{\left(1-\mu_{1}+p_{\mu} \cdot \mu_{1}\right)^{n-1}}{\left(1-p_{\mu}\right)^{n-1} \cdot \mu_{1}^{n-1}}\right)^{\frac{1}{n-1}}+\frac{1-\mu_{1}+p_{\mu} \cdot \mu_{1}}{\left(1-p_{\mu}\right) \cdot \mu_{1}}=1
$$

Moreover,

$$
\begin{array}{r}
\mathcal{B}_{l}\left(\underline{b}_{l}\right)=1-\left(\frac{\underline{b}_{l}+Q \cdot \pi_{2}\left(c_{l}, 1\right)-c_{l}}{\mu_{1}^{n-1} \cdot\left(1-p_{\mu}\right)^{n-1} \cdot\left(\underline{b}_{l}+Q \cdot \pi_{2}\left(c_{l}, 1\right)-c_{l}\right)}\right)^{\frac{1}{n-1}}+\frac{1-\mu_{1}+p_{\mu} \cdot \mu_{1}}{\left(1-p_{\mu}\right) \cdot \mu_{1}} \\
=1-\left(\frac{1}{\mu_{1}^{n-1} \cdot\left(1-p_{\mu}\right)^{n-1}}\right)^{\frac{1}{n-1}}+\frac{1-\mu_{1}+p_{\mu} \cdot \mu_{1}}{\left(1-p_{\mu}\right) \cdot \mu_{1}}=0 .
\end{array}
$$

\section{Proof of Proposition 5.}

The proof will proceed along nine steps that will build upon each other.

1. In any equilibrium $\operatorname{supp}\left(\mathcal{B}_{l}\right) \cap \operatorname{supp}\left(\mathcal{B}_{h}\right)$ is of measure 0 with respect to $\mathcal{B}_{l}$ and $\mathcal{B}_{h}$ or $\operatorname{supp}\left(\mathcal{B}_{l}\right) \cap \operatorname{supp}\left(\mathcal{B}_{h}\right)$ contains only one bid with a positive mass. That is, the supports of the strategy of the low-cost type and the high-cost type almost surely overlap in at most one bid.

2. $\bar{b}_{l} \leq \underline{b}_{h}$. That is, the low-cost type places lower bids than the high-cost type.

3. In any equilibrium $\bar{b}_{l}=\underline{b}_{h}$. That is, the supremum of the bids of the low-cost type is equal to the infinum of the bids of the high-cost type.

4. In any equilibrium $\mathcal{B}_{l}$ has no mass points beyond $\bar{b}_{l}$.

5. In any equilibrium $\mathcal{B}_{h}$ has no mass points beyond $\underline{b}_{h}$.

6. In any equilibrium $\operatorname{supp}\left(\mathcal{B}_{l}\right)$ and $\operatorname{supp}\left(\mathcal{B}_{h}\right)$ are connected. That is, the supports of the strategy of the low-cost type and the high-cost type do not have gaps.

7. $\underline{b}_{h} \geq c_{h}-Q \cdot \pi_{2}\left(c_{h}, \mu_{2}\right)$ with $\mu_{2}=s \cdot \mu_{1} /\left(1-\mu_{1}+s \cdot \mu_{1}\right)$ and $s$ the probability that a bidder of type $c_{l}$ chooses bid $\underline{b}_{h}$. That is, the high-cost type bids such that with every bid he makes at least an overall profit of 0 .

8. $\underline{b}_{h}=\bar{b}_{h}$. That is, the high-cost type plays a pure strategy in any equilibrium.

9. An equilibrium of the first-price auction always exists. 
In what follows we will denote by $\operatorname{Prob}(b)$ the probability of winning with bid $b$ in a previously selected equilibrium and $\mu_{2}(b)$ the equilibrium belief of the principal after observing the price $p=b$.

Step 1: In any equilibrium $\operatorname{supp}\left(\mathcal{B}_{l}\right) \cap \operatorname{supp}\left(\mathcal{B}_{h}\right)$ is of measure 0 with respect to $\mathcal{B}_{l}$ and $\mathcal{B}_{h}$ or $\operatorname{supp}\left(\mathcal{B}_{l}\right) \cap \operatorname{supp}\left(\mathcal{B}_{h}\right)$ contains only one bid with a positive mass. That is, the supports of the strategy of the low-cost type and the high-cost type almost sure overlap in at most one bid

Suppose otherwise, that is, an equilibrium where the supports overlap exists. In this case there exists $b^{\prime}, b^{\prime \prime}$ in $\operatorname{supp}\left(\mathcal{B}_{l}\right) \cap \operatorname{supp}\left(\mathcal{B}_{h}\right)$ such that

$$
\operatorname{Prob}\left(b^{\prime}\right) \cdot\left(b^{\prime}-c_{l}+Q \cdot \pi_{2}\left(c_{l}, \mu_{2}\left(b^{\prime}\right)\right)\right)=\operatorname{Prob}\left(b^{\prime \prime}\right) \cdot\left(b^{\prime \prime}-c_{l}+Q \cdot \pi_{2}\left(c_{l}, \mu_{2}\left(b^{\prime \prime}\right)\right)\right)
$$

and

$$
\operatorname{Prob}\left(b^{\prime}\right) \cdot\left(b^{\prime}-c_{h}+Q \cdot \pi_{2}\left(c_{h}, \mu_{2}\left(b^{\prime}\right)\right)\right)=\operatorname{Prob}\left(b^{\prime \prime}\right) \cdot\left(b^{\prime \prime}-c_{h}+Q \cdot \pi_{2}\left(c_{h}, \mu_{2}\left(b^{\prime \prime}\right)\right)\right) .
$$

In other words, as $b^{\prime}$ and $b^{\prime \prime}$ are both in $\operatorname{supp}\left(\mathcal{B}_{l}\right) \cap \operatorname{supp}\left(\mathcal{B}_{h}\right)$ both types of supplier must be indifferent between bidding $b^{\prime}$ and $b^{\prime \prime}$. Subtracting both equations from each other yields

$$
\begin{aligned}
\left(\operatorname{Prob}\left(b^{\prime}\right)-\operatorname{Prob}\left(b^{\prime \prime}\right)\right) & \cdot\left(c_{l}-c_{h}+Q \cdot \pi_{2}\left(c_{h}, \mu_{2}\left(b^{\prime \prime}\right)\right)-\right. \\
Q & \left.\cdot \pi_{2}\left(c_{l}, \mu_{2}\left(b^{\prime \prime}\right)\right)+Q \cdot \pi_{2}\left(c_{h}, \mu_{2}\left(b^{\prime}\right)\right)-Q \cdot \pi_{2}\left(c_{l}, \mu_{2}\left(b^{\prime}\right)\right)\right)=0 .
\end{aligned}
$$

As $c_{l}-c_{h}+Q \cdot \pi_{2}\left(c_{h}, \mu_{2}\left(b^{\prime \prime}\right)\right)-Q \cdot \pi_{2}\left(c_{l}, \mu_{2}\left(b^{\prime \prime}\right)\right)+Q \cdot \pi_{2}\left(c_{h}, \mu_{2}\left(b^{\prime}\right)\right)-Q \cdot \pi_{2}\left(c_{l}, \mu_{2}\left(b^{\prime}\right)\right)$ is strictly below zero, this implies that $\operatorname{Prob}\left(b^{\prime}\right)-\operatorname{Prob}\left(b^{\prime \prime}\right)$ has to be zero. This is a contradiction to the initial assumption.

Step 2: $\bar{b}_{l} \leq \underline{b}_{h}$. That is, the low-cost type places lower bids then the high-cost type.

Suppose otherwise. In this case, by Step 1, there exists an equilibrium, $b^{\prime} \in$ $\operatorname{supp}\left(\mathcal{B}_{l}\right) \backslash \operatorname{supp}\left(\mathcal{B}_{h}\right)$ and $b^{\prime \prime} \in \operatorname{supp}\left(\mathcal{B}_{h}\right) \backslash \operatorname{supp}\left(\mathcal{B}_{l}\right)$ such that $\operatorname{Prob}\left(b^{\prime \prime}\right)>\operatorname{Prob}\left(b^{\prime}\right)$ and

$$
\operatorname{Prob}\left(b^{\prime}\right) \cdot\left(b^{\prime}-c_{l}+Q \cdot \pi_{2}\left(c_{l}, 1\right)\right) \geq \operatorname{Prob}\left(b^{\prime \prime}\right) \cdot\left(b^{\prime \prime}-c_{l}+Q \cdot \pi_{2}\left(c_{l}, 0\right)\right)
$$

and

$$
\operatorname{Prob}\left(b^{\prime \prime}\right) \cdot\left(b^{\prime \prime}-c_{h}+Q \cdot \pi_{2}\left(c_{h}, 0\right)\right) \geq \operatorname{Prob}\left(b^{\prime}\right) \cdot\left(b^{\prime}-c_{h}+Q \cdot \pi_{2}\left(c_{h}, 1\right)\right) .
$$


Subtracting both inequalities gives

$\operatorname{Prob}\left(b^{\prime}\right) \cdot\left(c_{h}-c_{l}+Q \cdot \pi_{2}\left(c_{l}, 1\right)-Q \cdot \pi_{2}\left(c_{h}, 1\right)\right) \geq \operatorname{Prob}\left(b^{\prime \prime}\right) \cdot\left(c_{h}-c_{l}+Q \cdot \pi_{2}\left(c_{l}, 0\right)-Q \cdot \pi_{2}\left(c_{h}, 0\right)\right)$.

Thus, for a contradiction it remains to show that

$$
\pi_{2}\left(c_{l}, 1\right)-\pi_{2}\left(c_{h}, 1\right) \leq \pi_{2}\left(c_{l}, 0\right)-\pi_{2}\left(c_{h}, 0\right)
$$

By Definition 1 this is

$$
\begin{aligned}
\int_{\underline{c}_{l}}^{P(1)}(P(1)-c) \mathrm{d} F_{l}(c)- & \int_{\underline{c}_{h}}^{P(1)}(P(1)-c) \mathrm{d} F_{h}(c) \\
& \leq \int_{\underline{c}_{l}}^{P(0)}(P(0)-c) \mathrm{d} F_{l}(c)-\int_{\underline{c}_{h}}^{P(0)}(P(0)-c) \mathrm{d} F_{h}(c) .
\end{aligned}
$$

Due to $P(1)<P(0)$, inequality (43) is true if

$$
\begin{aligned}
\int_{\underline{c}_{l}}^{P(1)}(P(1)-c) \mathrm{d} F_{l}(c)-\int_{\underline{c}_{h}}^{P(0)} & (P(1)-c) \mathrm{d} F_{h}(c) \\
\leq & \int_{\underline{c}_{l}}^{P(1)}(P(0)-c) \mathrm{d} F_{l}(c)-\int_{\underline{c}_{h}}^{P(0)}(P(0)-c) \mathrm{d} F_{h}(c)
\end{aligned}
$$

is true. Rearanging gives

$$
\int_{\underline{c}_{l}}^{P(1)} P(1)-P(0) \mathrm{d} F_{l}(c)-\int_{\underline{c}_{h}}^{P(0)} P(1)-P(0) \mathrm{d} F_{h}(c) \leq 0,
$$

which is true by Assumption 1 and Lemma 2.

Step 3: In any equilibrium $\bar{b}_{l}=\underline{b}_{h}$. That is, the supremum of the bids of the low-cost type is equal to the infinum of the bids of the high-cost type.

For a contradiction suppose $\bar{b}_{l}<\underline{b}_{h} \cdot{ }^{35}$ In this case, $\bar{b}_{l}$ cannot be a mass point as $\operatorname{Prob}\left(\bar{b}_{l}\right)<\lim _{\epsilon \rightarrow 0} \operatorname{Prob}\left(\bar{b}_{l}-\epsilon\right)$. Consequently, the expected payoff of a bidder of type $c_{l}, \operatorname{Prob}(b) \cdot\left(b-c_{l}+Q \cdot \pi_{2}\left(c_{l}, 1\right)\right)$, exhibits a jump at $\bar{b}_{l}$ and we have $\lim _{\epsilon \rightarrow 0} \operatorname{Prob}\left(\bar{b}_{l}-\right.$ $\epsilon) \cdot\left(\bar{b}_{l}-\epsilon-c_{l}+Q \cdot \pi_{2}\left(c_{l}, 1\right)\right)>\operatorname{Prob}\left(\bar{b}_{l}\right) \cdot\left(\bar{b}_{l}-c_{l}+Q \cdot \pi_{2}\left(c_{l}, 1\right)\right) .{ }^{36}$ This contradicts that $\bar{b}_{l}$ is in the support of the equilibrium bid distribution. As $\bar{b}_{l}$ cannot be a mass point, $\bar{b}_{l}<\underline{b}_{h}$ implies $\lim _{\epsilon \rightarrow 0} \operatorname{Prob}\left(\underline{b}_{h}-\epsilon\right)=\operatorname{Prob}\left(\bar{b}_{l}\right)$. Thus, $\lim _{\epsilon \rightarrow 0} \operatorname{Prob}\left(\underline{b}_{h}-\epsilon\right) \cdot\left(\underline{b}_{h}-\epsilon-\right.$ $\left.c_{l}+Q \pi_{2}\left(c_{l}, 1\right)\right)>\operatorname{Prob}\left(\bar{b}_{l}\right) \cdot\left(\bar{b}_{l}-c_{l}+Q \pi_{2}\left(c_{l}, 1\right)\right)$. A contradiction.

Step 4: In any equilibrium $\mathcal{B}_{l}$ has no mass points beyond $\bar{b}_{l}$.

Suppose otherwise, that is, there is an equilibrium with a $b^{\prime}<\bar{b}_{l}$ such that

\footnotetext{
${ }^{35} \bar{b}_{l}>\underline{b}_{h}$ is ruled out by Step 2 .

${ }^{36} \mu_{2}=1$ by Step 1 and Step 2 .
} 
$b_{l}\left(b^{\prime}\right)>0$. In this equilibrium $\operatorname{Prob}(\cdot)$ exhibits a jump at $b^{\prime}$ in particular, $\operatorname{Prob}\left(b^{\prime}\right)<$ $\lim _{\epsilon \rightarrow 0} \operatorname{Prob}\left(b^{\prime}-\epsilon\right)$. Consequently, the expected payoff of a bidder of type $c_{l}, \operatorname{Prob}(b)$. $\left(b-c_{l}+Q \cdot \pi_{2}\left(c_{l}, 1\right)\right)$, exhibits a jump at $b^{\prime}$ and we have $\lim _{\epsilon \rightarrow 0} \operatorname{Prob}\left(b^{\prime}-\epsilon\right) \cdot\left(b^{\prime}-\epsilon-\right.$ $\left.c_{l}+Q \cdot \pi_{2}\left(c_{l}, 1\right)\right)>\operatorname{Prob}\left(b^{\prime}\right) \cdot\left(b^{\prime}-c_{l}+Q \cdot \pi_{2}\left(c_{l}, 1\right)\right) .{ }^{37}$ This contradicts that $b^{\prime}$ is in the support of the equilibrium bid distribution.

Step 5: In any equilibrium $\mathcal{B}_{h}$ has no mass points beyond $\underline{b}_{h}$.

Suppose otherwise, that is, there is an equilibrium with a mass point in $b^{\prime}>$ $\underline{b}_{h}$. In this equilibrium $\operatorname{Prob}(\cdot)$ exhibits a jump at $b^{\prime}$ in particular, $\operatorname{Prob}\left(b^{\prime}\right)<$ $\lim _{\epsilon \rightarrow 0} \operatorname{Prob}\left(b^{\prime}-\epsilon\right)$. Consequently, the expected payoff of a bidder of type $c_{h}, \operatorname{Prob}(b)$. $\left(b-c_{h}+\pi_{2}\left(c_{h}, 0\right)\right)$, exhibits a jump at $b^{\prime}$ and we have $\lim _{\epsilon \rightarrow 0} \operatorname{Prob}\left(b^{\prime}-\epsilon\right) \cdot\left(b^{\prime}-\epsilon-c_{h}+\right.$ $\left.\pi_{2}\left(c_{h}, 0\right)\right)>\operatorname{Prob}\left(b^{\prime}\right) \cdot\left(b^{\prime}-c_{h}+\pi_{2}\left(c_{h}, 0\right)\right) .{ }^{38}$ This contradicts that $b^{\prime}$ is in the support of the equilibrium bid distribution.

Step 6: In any equilibrium $\operatorname{supp}\left(\mathcal{B}_{l}\right)$ and $\operatorname{supp}\left(\mathcal{B}_{h}\right)$ are connected. That is, the supports of the strategy of the low-cost type and the high-cost type do not have gaps.

Suppose otherwise, that is, there exists an interval $\left(b^{\prime}, b^{\prime \prime}\right)$ with $b^{\prime}>\underline{b}_{l}$ and $b^{\prime \prime}<\bar{b}_{l}$, $b_{l}(b)=0$ for all $b \in\left(b^{\prime}, b^{\prime \prime}\right)$ and $b^{\prime}, b^{\prime \prime} \in \operatorname{supp}\left(\mathcal{B}_{l}\right) .{ }^{39}$ By Step 1 and Step 2 it follows that also $b_{h}(b)=0$ for all $b \in\left[b^{\prime}, b^{\prime \prime}\right]$. Thus, by Step 1 to Step 3, it follows that $\operatorname{Prob}\left(b^{\prime}\right)=$ $\operatorname{Prob}\left(b^{\prime \prime}\right)$ and the payoff of type $c_{l}$ from bidding $b^{\prime}, \operatorname{Prob}\left(b^{\prime}\right) \cdot\left(b^{\prime}-c_{l}+\pi_{2}\left(c_{l}, 1\right)\right)$, is strictly smaller then the payoff from bidding $b^{\prime \prime}, P\left(b^{\prime \prime}\right) \cdot\left(b^{\prime \prime}-c_{l}+\pi_{2}\left(c_{l}, 1\right)\right)$. This contradicts that $b^{\prime}$ is in the support of the equilibrium bid distribution.

Step \%: $\underline{b}_{h} \geq c_{h}-Q \cdot \pi_{2}\left(c_{h}, \mu_{2}\right)$ with $\mu_{2}=s \cdot \mu_{1} /\left(1-\mu_{1}+s \cdot \mu_{1}\right)$ and $s$ the probability that a bidder of type $c_{l}$ chooses bid $\underline{b}_{h}$. That is, the high-cost type bids such that with every bid he makes at least an overall profit of 0 .

The proof of step 7 is obvious.

Step 8: $\underline{b}_{h}=\bar{b}_{h}$. That is, the high-cost type plays a pure strategy in any equilibrium.

Suppose otherwise. In this case, due to Step $5, \operatorname{Prob}\left(\bar{b}_{h}\right)=0$. Moreover, due to Step 7, there exists a $b^{\prime}<\bar{b}_{h}$ such that $b^{\prime}-c_{h}+\pi_{2}\left(c_{h}, 0\right)>0$ and $\operatorname{Prob}\left(b^{\prime}\right)>0$ and thus $\operatorname{Prob}\left(b^{\prime}\right) \cdot\left(b^{\prime}-c_{h}+\pi_{2}\left(c_{h}, 0\right)\right)>0$, a contradiction.

Step 9: An equilibrium of the first-price auction exists. Consider the equilibrium characterizations from Proposition 2, Proposition 3, and Proposition 4. Suppose there is no separating or full pooling equilibrium, then there exists a $\mu_{2}$ and a $b_{h}$ such that conditions (12), (13) and (14) define $\mu_{2}$ implicitly by the solution to

$$
Q \cdot\left[(n-1) \cdot \pi_{2}\left(c_{h}, \mu_{2}\right)+\pi_{2}\left(c_{l}, \mu_{2}\right)-n \cdot \pi_{2}\left(c_{l}, 1\right)\right]=(n-1) \cdot\left(c_{h}-c_{l}\right)
$$

and $b_{h}$ by $b_{h}=c_{h}-Q \cdot \pi_{2}\left(c_{h}, \mu_{2}\right)$. Observe that if no full pooling equilibrium exists,

\footnotetext{
${ }^{37} \mu_{2}=1$ by Step 1 and Step 2 .

${ }^{38} \mu_{2}=0$ by Step 1 and Step 2 .

${ }^{39}$ The argument for $c_{h}$ proceeds in exactly the same manner.
} 
conditions (2), (3), and (4) imply

$$
Q \cdot\left[(n-1) \cdot \pi_{2}\left(c_{h}, \mu_{1}\right)+\pi_{2}\left(c_{l}, \mu_{1}\right)-n \cdot \pi_{2}\left(c_{l}, 1\right)\right]<(n-1) \cdot\left(c_{h}-c_{l}\right)
$$

Moreover, if no separating equilibrium exists, conditions (6), (7), and (8) imply

$$
Q \cdot\left[(n-1) \cdot \pi_{2}\left(c_{h}, 0\right)+\pi_{2}\left(c_{l}, 0\right)-n \cdot \pi_{2}\left(c_{l}, 1\right)\right]>(n-1) \cdot\left(c_{h}-c_{l}\right) .
$$

Thus, a solution to equation (44) exists and $\mu_{2}$ is well defined. Obviously $b_{h}$ then satisfies conditions (12), (13), and (14). Summing up, whenever a separating and pooling equilibrium fails to exist, there exists a partial-pooling equilibrium. It follows, an equilibrium of the first-price auction always exists.

\section{A.2 Proofs of Section 4}

\section{Proof of Lemma 3.}

Observe that in a full pooling equilibrium the expected second-period buyer surplus is strictly higher in the second-price auction than in the first-price auction. This is due to the fact that in the second-price auction the types separate with positive probability and the buyer receives some information for the second period. In the full pooling equilibrium of the first-price auction, the types never separate and the buyer will decide in the second period based on her prior. Thus, the buyer surplus is always better in the second-price auction than in the full pooling equilibrium of the first-price auction. To prove the claim we show that the second-price auction also generates a higher buyer surplus in the first period. This, however, is obvious as the highest possible bid in the second-price auction

$$
c_{h}-Q \cdot \pi_{2}\left(c_{h}, \frac{n \cdot\left(1-\mu_{1}\right)^{n-1} \cdot \mu_{1}}{n \cdot\left(1-\mu_{1}\right)^{n-1} \cdot \mu_{1}+\left(1-\mu_{1}\right)^{n}}\right)
$$

is by Lemma 2 smaller than the lowest possible bid in the pooling equilibrium of the first-price auction

$$
c_{h}-Q \cdot \pi_{2}\left(c_{h}, \mu_{1}\right)
$$

\section{Proof of Proposition 6}

If Condition (5) holds, Corollary 1 ensures that there exists a $Q_{\text {pool }}$ such that for all $Q>Q_{\text {pool }}$ a pooling equilibrium exists in the first-price auction.

Comparing conditions (12),(13), and (14) from Proposition 4 ensures that whenever Condition (5) holds, there exists a $Q_{\text {part }}$ such that a partial pooling equilibrium 
fails to exist for all $Q>Q_{\text {part }}$.

If $n \cdot\left(\pi_{2}\left(c_{h}, 1\right)-\pi_{2}\left(c_{l}, 1\right)\right)+\pi_{2}\left(c_{l}, 0\right)-\pi_{2}\left(c_{h}, 0\right)>0$, there exist a $Q_{\text {sep }}$ such that for all $Q>Q_{\text {sep }}$ condition (6) and condition (8) contradict each other and thus a separating equilibrium fails to exist. We show that $n \cdot\left(\pi_{2}\left(c_{h}, 1\right)-\pi_{2}\left(c_{l}, 1\right)\right)+\pi_{2}\left(c_{l}, 0\right)-\pi_{2}\left(c_{h}, 0\right)>0$ is implied by Condition (5). That is, we have to show that

$$
\begin{aligned}
\pi_{2}\left(c_{l}, \mu_{1}\right)-\pi_{2}\left(c_{h}, \mu_{1}\right)>n \cdot\left[\pi_{2}\left(c_{l}, 1\right)-\pi_{2}\left(c_{h}, \mu_{1}\right)\right] & \Rightarrow \\
\pi_{2}\left(c_{l}, 0\right)-\pi_{2}\left(c_{h}, 0\right) & >n \cdot\left[\pi_{2}\left(c_{l}, 1\right)-\pi_{2}\left(c_{h}, 1\right)\right] .
\end{aligned}
$$

As $\pi_{2}\left(c_{h}, \mu_{1}\right) \geq \pi_{2}\left(c_{h}, 1\right)$ it suffices to show that $\pi_{2}\left(c_{l}, 0\right)-\pi_{2}\left(c_{h}, 0\right) \geq \pi_{2}\left(c_{l}, \mu_{1}\right)-$ $\pi_{2}\left(c_{h}, \mu_{1}\right)$ which can be rearanged to give

$$
\begin{aligned}
& \int_{\underline{\mathbf{C}}_{l}}^{P(0)}(P(0)-c) \mathrm{d} F_{l}-\int_{\underline{\mathbf{c}}_{h}}^{P(0)}(P(0)-c) \mathrm{d} F_{h} \geq \int_{\underline{\mathbf{c}}_{l}}^{P\left(\mu_{1}\right)}\left(P\left(\mu_{1}\right)-c\right) \mathrm{d} F_{l} \\
& -\int_{\underline{\mathbf{c}}_{h}}^{P\left(\mu_{1}\right)}\left(P\left(\mu_{1}\right)-c\right) \mathrm{d} F_{h} \\
& \Leftrightarrow \int_{\underline{\mathbf{C}}_{l}}^{P(0)}(P(0)-c) \mathrm{d} F_{l}-\int_{\underline{\mathbf{c}}_{l}}^{P\left(\mu_{1}\right)}\left(P\left(\mu_{1}\right)-c\right) \mathrm{d} F_{l} \geq \int_{\underline{\mathbf{C}}_{h}}^{P(0)}(P(0)-c) \mathrm{d} F_{h} \\
& -\int_{\underline{\mathbf{c}}_{h}}^{P\left(\mu_{1}\right)}\left(P\left(\mu_{1}\right)-c\right) \mathrm{d} F_{h} \\
& \Leftarrow \int_{\underline{\mathbf{c}}_{h}}^{P(0)}(P(0)-c) \mathrm{d} F_{l}-\int_{\underline{\mathbf{c}}_{h}}^{P\left(\mu_{1}\right)}\left(P\left(\mu_{1}\right)-c\right) \mathrm{d} F_{l} \geq \int_{\underline{\mathbf{c}}_{h}}^{P(0)}(P(0)-c) \mathrm{d} F_{h} \\
& -\int_{\underline{\mathbf{C}}_{h}}^{P\left(\mu_{1}\right)}\left(P\left(\mu_{1}\right)-c\right) \mathrm{d} F_{h} \\
& \Leftarrow \int_{\underline{\underline{C}}_{h}}^{P(0)}\left(\left(P(0)-P\left(\mu_{1}\right)\right) \mathrm{d} F_{l}+\int_{P(0)}^{P\left(\mu_{1}\right)}\left(c-P\left(\mu_{1}\right)\right) \mathrm{d} F_{l} \geq \int_{\underline{\mathbf{C}}_{h}}^{P(0)}\left(\left(P(0)-P\left(\mu_{1}\right)\right) \mathrm{d} F_{h}+\right.\right. \\
& \int_{P(0)}^{P\left(\mu_{1}\right)}\left(c-P\left(\mu_{1}\right)\right) \mathrm{d} F_{h} .
\end{aligned}
$$

The last inequality is true by assumption 1 part 2 .

Set $\bar{Q}=\max \left\{Q_{\text {pool }}, Q_{\text {part }}, Q_{\text {sep }}\right\}$. Then for all $Q>\bar{Q}$ the only equilibria of the first-price auction are pooling equilibria. By Lemma 3, the best such equilibrium yields a lower buyer surplus then the second-price auction. 


\section{Proof of Proposition 7.}

Observe that in a separating equilibrium the expected second-period buyer surplus is strictly higher in the first-price auction than in the second-price auction. This is due to the fact, that in a separating equilibrium the buyer receives the best possible information for her decision in the second period. In the second-price auction, whenever the buyer observes the higher bid

$$
c_{h}-Q \cdot \pi_{2}\left(c_{h}, \frac{n \cdot\left(1-\mu_{1}\right)^{n-1} \cdot \mu_{1}}{n \cdot\left(1-\mu_{1}\right)^{n-1} \cdot \mu_{1}+\left(1-\mu_{1}\right)^{n}}\right)
$$

she is not fully sure whether she faces the low-cost or the high-cost type. Thus, the buyer surplus for the second period is always better in the separating equilibrium of the first-price auction. To prove the claim we show that the first-price auction also generates a higher buyer surplus in the first period. Observe, that the allocation in both, the separating equilibrium of the first-price auction and the second-price auction, are efficient. To show that the first-price auction generates more revenue, we demonstrate that the surplus of the bidders in period one is lower in the separating equilibrium of the first-price auction than in the second-price auction.

Consider first the high-cost type $c_{h}$. His surplus from period one in the separating equilibrium of the first-price auction:

$$
\frac{1}{n-1} \cdot\left(1-\mu_{1}\right)^{n-1} \cdot\left(c_{h}-Q \cdot \pi_{2}\left(c_{h}, 0\right)-c_{h}\right)
$$

The payoff of the high-cost type from period one of the second-price auction is:

$$
\frac{1}{n-1} \cdot\left(1-\mu_{1}\right)^{n-1} \cdot\left(c_{h}-Q \cdot \pi_{2}\left(c_{h}, \frac{n \cdot\left(1-\mu_{1}\right)^{n-1} \cdot \mu_{1}}{n \cdot\left(1-\mu_{1}\right)^{n-1} \cdot \mu_{1}+\left(1-\mu_{1}\right)^{n}}\right)-c_{h}\right) .
$$

Due to Lemma 2 the former is lower than the later. Now consider the payoff of the low-cost type. From expression (37) we get his overall expected payoff from both periods. Thus, subtracting the expected second-period payoff we get for the expected first-period payoff of the low-cost type in the separating equilibrium of the first-price auction:

$$
\begin{aligned}
\left(1-\mu_{1}\right)^{n-1} \cdot\left(c_{h}-Q \cdot \pi_{2}\left(c_{h}, 0\right)+\pi_{2}\left(c_{l}, 1\right)\right. & \left.-c_{l}\right)-\left(1-\mu_{1}\right)^{n-1} \cdot \pi_{2}\left(c_{l}, 1\right) \\
& -\sum_{k=1}^{n-1} \frac{1}{k} \cdot \mu_{1}^{k} \cdot\left(1-\mu_{1}\right)^{n-1-k} \cdot \pi_{2}\left(c_{l}, 1\right) .
\end{aligned}
$$


Which is equal to

$$
\left(1-\mu_{1}\right)^{n-1} \cdot\left(c_{h}-Q \cdot \pi_{2}\left(c_{h}, 0\right)-c_{l}\right)-\sum_{k=1}^{n-1} \frac{1}{k} \cdot \mu_{1}^{k}\left(1-\mu_{1}\right)^{n-1-k} \cdot \pi_{2}\left(c_{l}, 1\right) .
$$

For the second-price auction the same approach yields

$$
\begin{aligned}
&\left(1-\mu_{1}\right)^{n-1} \cdot( c_{h}-Q \cdot \pi_{2}\left(c_{h}, \frac{n \cdot\left(1-\mu_{1}\right)^{n-1} \cdot \mu_{1}}{n \cdot\left(1-\mu_{1}\right)^{n-1} \cdot \mu_{1}+\left(1-\mu_{1}\right)^{n}}\right) \\
&\left.+\pi_{2}\left(c_{l}, \frac{n \cdot\left(1-\mu_{1}\right)^{n-1} \cdot \mu_{1}}{n \cdot\left(1-\mu_{1}\right)^{n-1} \cdot \mu_{1}+\left(1-\mu_{1}\right)^{n}}\right)-c_{l}\right) \\
&-\left(1-\mu_{1}\right)^{n-1} \cdot \pi_{2}\left(c_{l}, \frac{n \cdot\left(1-\mu_{1}\right)^{n-1} \cdot \mu_{1}}{n\left(1-\mu_{1}\right)^{n-1} \cdot \mu_{1}+\left(1-\mu_{1}\right)^{n}}\right) \\
&-\sum_{k=1}^{n-1} \frac{1}{k} \cdot \mu_{1}^{k} \cdot\left(1-\mu_{1}\right)^{n-1-k} \cdot \pi_{2}\left(c_{l}, 1\right) .
\end{aligned}
$$

Which is equal to

$$
\begin{array}{r}
\left(1-\mu_{1}\right)^{n-1} \cdot\left(c_{h}-Q \cdot \pi_{2}\left(c_{h}, \frac{n \cdot\left(1-\mu_{1}\right)^{n-1} \cdot \mu_{1}}{n \cdot\left(1-\mu_{1}\right)^{n-1} \cdot \mu_{1}+\left(1-\mu_{1}\right)^{n}}\right)-c_{l}\right) \\
-\sum_{k=1}^{n-1} \frac{1}{k} \cdot \mu_{1}^{k} \cdot\left(1-\mu_{1}\right)^{n-1-k} \cdot \pi_{2}\left(c_{l}, 1\right)
\end{array}
$$

Due to Lemma 2 directly comparing (48) and (49) yields that the low-cost type earns a lower payoff in the separating equilibrium.

\section{A.3 Proofs of Section 5.}

\section{Proof of Lemma 4.}

Invoking a revelation principle allows us to focus on direct mechanisms in which suppliers report their costs truthfully in each period without loss of generality. A direct mechanism consists of functions $x, p, X^{i}$ and $P^{i}$, where ${ }^{40}$

$$
\begin{aligned}
& x: \mathcal{C} \rightarrow \Delta, \\
& p: \mathcal{C} \rightarrow \mathbb{R}^{n}, \\
& X^{i}: \mathcal{C} \times\left[\underline{c}^{i}, \bar{c}^{i}\right] \rightarrow[0,1], \\
& P^{i}: \mathcal{C} \times\left[\underline{c}^{i}, \bar{c}^{i}\right] \rightarrow[0,1] .
\end{aligned}
$$

\footnotetext{
${ }^{40}$ Formally, $\Delta$ is defined as $\Delta \equiv\left\{\left(x^{1}, \ldots, x^{n}\right) \mid 0 \leq x^{i} \leq 1\right.$ for all $i$, and $\left.\sum_{i} x^{i} \leq 1\right\}$.
} 
The mechanism asks suppliers' to report their first-period costs, which jointly determine the contract supplier (via $x(\mathbf{c})$ ) and a first-period payment vector $p(\mathbf{c})$. The contract supplier enters period two, and is asked for reporting his second-period costs. The report, together with the vector of first-period reports, determines whether the good is supplied in period two and the second-period transfer $P^{i}(\mathbf{c}, c)$. Notice that the possible reports in period two directly depend on the contract supplier's first-period report: the direct mechanism does not allow for inconsistent reports.

A direct mechanism is incentive compatible if each supplier prefers reporting all information truthfully. To make this precise we use the following short-hand notations. For all $\mathbf{c} \in \mathcal{C}$ and $c \in\left[\underline{c}^{i}, \bar{c}^{i}\right]$ let $u^{i}(\mathbf{c}, c)=P^{i}(\mathbf{c}, c)-c \cdot Q \cdot X^{i}(\mathbf{c}, c)$. Further let $\rho^{i}\left(c_{s}\right)=\sum_{\mathbf{c}^{-i}} \operatorname{Prob}\left(\mathbf{c}^{-i}\right) \cdot p^{i}\left(c_{\theta}, \mathbf{c}^{-i}\right)$ for $\theta=l, h$ and let

$$
U^{i}\left(c_{\theta}\right)=\rho^{i}\left(c_{\theta}\right)+\sum_{\mathbf{c}^{-i}} \operatorname{Prob}\left(\mathbf{c}^{-i}\right) \cdot x^{i}\left(c_{\theta}, \mathbf{c}^{-i}\right)\left[-c_{\theta}+\int_{\underline{c}_{\theta}}^{\bar{c}_{\theta}} u^{i}\left(c_{\theta}, \mathbf{c}^{-i}, c\right) \mathrm{d} F_{\theta}(c)\right] .
$$

A direct mechanism is incentive compatible, if

(i) it is incentive compatible with respect to the second-period type

$$
u^{i}(\mathbf{c}, c) \geq P^{i}\left(\mathbf{c}, c^{\prime}\right)-c \cdot Q \cdot X^{i}\left(\mathbf{c}, c^{\prime}\right) \quad \text { for all } \vec{c} \in \mathcal{C}, \text { and } c, c^{\prime} \in\left[\underline{c}^{i}, \bar{c}^{i}\right]
$$

(ii) it is incentive compatible with respect to the ex-ante type

$$
\begin{aligned}
U^{i}\left(c_{\theta}\right) \geq \rho^{i}\left(c_{\theta^{\prime}}\right) & +\sum_{\mathbf{c}^{-i}} \operatorname{Prob}\left(\mathbf{c}^{-i}\right) \cdot x^{i}\left(c_{\theta^{\prime}}, \mathbf{c}^{-i}\right) \cdot\left[-c_{\theta}\right. \\
+ & \left.\int_{\underline{c}_{\theta}}^{\bar{c}_{\theta}} P^{i}\left(c_{\theta^{\prime}}, \mathbf{c}^{-i}, \varphi(c)\right)-c \cdot Q \cdot X^{i}\left(c_{\theta^{\prime}}, \mathbf{c}^{-i}, \varphi(c)\right) \mathrm{d} F_{\theta}(c)\right]
\end{aligned}
$$

for all $\theta, \theta^{\prime} \in\{l, h\}$ and all mappings $\varphi:\left[\underline{c}_{\theta}, \bar{c}_{\theta}\right] \rightarrow\left[\underline{c}_{\theta^{\prime}}, \bar{c}_{\theta^{\prime}}\right]$.

The latter constraint explicitly takes into account double deviations, where the supplier misrepresents her first-period costs and subsequently mis-represents her secondperiod costs as well. In contrast, the first constraint is only posed for truthful firstperiod reports. ${ }^{41}$

Second-period incentive constraints are straightforward to characterize, we have the following:

\footnotetext{
${ }^{41}$ Note, that we need to specify second-period incentive constraints only along the equilibrium path, i.e. for cost reports that are consistent with the supplier's announcement in period one. For any inconsistent report we can set the supplier's transfer to a large negative number deterring such report profiles.
} 
Lemma A.1. Second-period incentive constraints (54) are satisfied if and only if (i) $X^{i}(\mathbf{c}, c)$ is non-increasing for all $\mathbf{c} \in \mathcal{C},($ ii $) \partial u^{i}(\mathbf{c}, c) / \partial c=X^{i}(\mathbf{c}, c)$ almost everywhere, and (iii)

$$
u^{i}(\mathbf{c}, c)=u^{i}\left(\mathbf{c}, \bar{c}^{i}\right)+Q \cdot \int_{c}^{\bar{c}^{i}} X^{i}(\mathbf{c}, s) \mathrm{d} s
$$

Proof. The proof is standard and therefore omitted.

In the following we consider a relaxed program that disregards the high-cost supplier's incentive constraint. In this relaxed program a low-cost supplier's first-period incentive constraint and a high-cost supplier's participation constraint are both binding. The latter yields $U^{i}\left(c_{h}\right)=0$. Notice that following (54) the supplier who reported $c_{h}$ in period one and was selected as contract supplier reports her second period costs truthfully whenever these lie in the interval $\left[\underline{c}_{h}, \bar{c}_{h}\right]$. However, if $c<\underline{c}_{h}$ the supplier can not report second-period costs truthfully, since he is only allowed to report costs in the interval $\left[\underline{c}_{h}, \bar{c}_{h}\right]$. Following Lemma A.1, we have for all $c^{\prime} \in\left[\underline{c}_{h}, \bar{c}_{h}\right]$

$$
P^{i}\left(c_{h}, \mathbf{c}^{-i}, c^{\prime}\right)-c \cdot X^{i}\left(c_{h}, \mathbf{c}^{-i}, c^{\prime}\right)=u^{i}\left(c_{h}, \mathbf{c}^{-i}, c^{\prime}\right)+\left(c^{\prime}-c\right) \cdot X^{i}\left(c_{h}, \mathbf{c}^{-i}, c^{\prime}\right)
$$

Hence,

$$
\begin{aligned}
P^{i}\left(c_{h}, \mathbf{c}^{-i}, c^{\prime}\right)-c \cdot X^{i}\left(c_{h}, \mathbf{c}^{-i}, c^{\prime}\right)= & P^{i}\left(c_{h}, \mathbf{c}^{-i}, \underline{c}_{h}\right)-c \cdot X^{i}\left(c_{h}, \mathbf{c}^{-i}, \underline{c}_{h}\right) \\
& +\int_{\underline{c}_{h}}^{c^{\prime}}\left(X^{i}\left(c_{h}, \mathbf{c}^{-i}, c^{\prime}\right)-X^{i}\left(c_{h}, \mathbf{c}^{-i}, s\right) \mathrm{d} s\right. \\
& +\left(\underline{c}_{h}-c\right) \cdot\left(X^{i}\left(c_{h}, \mathbf{c}^{-i}, c^{\prime}\right)-X^{i}\left(c_{h}, \mathbf{c}^{-i}, \underline{c}_{h}\right)\right) \\
\leq & P^{i}\left(c_{h}, \mathbf{c}^{-i}, \underline{c}_{h}\right)-c \cdot X^{i}\left(c_{h}, \mathbf{c}^{-i}, \underline{c}_{h}\right) .
\end{aligned}
$$

The last inequality uses that $X_{i}^{2}\left(c_{h}, \mathbf{c}^{-i}, s\right)$ weakly decreases in $s$. Hence, the contract supplier's optimal reporting strategy satisfies

$$
\varphi(c)= \begin{cases}c, & c \geq \underline{c}_{h} \\ \underline{c}_{h}, & c<\underline{c}_{h} .\end{cases}
$$


Using this, we get

$$
\begin{aligned}
& U^{i}\left(c_{l}\right)=\rho^{i}\left(c_{h}\right)+\sum_{\mathbf{c}^{-i}} \operatorname{Prob}\left(\mathbf{c}^{-i}\right) x^{i}\left(c_{h}, \mathbf{c}^{-i}\right)\left[-c_{l}\right. \\
& \left.+\int_{\underline{c}_{l}}^{\bar{c}_{l}} \max _{r \in\left[\underline{c}_{h}, \bar{c}_{h}\right]} P^{i}\left(c_{h}, \mathbf{c}^{-i}, r\right)-c Q X^{i}\left(c_{h}, \mathbf{c}^{-i}, r\right) \mathrm{d} F_{l}(c)\right] \\
& =U^{i}\left(c_{h}\right)+\sum_{\mathbf{c}^{-i}} \operatorname{Prob}\left(\mathbf{c}^{-i}\right) x^{i}\left(c_{h}, \mathbf{c}^{-i}\right)\left\{\Delta c-\int_{\underline{c}_{h}}^{\bar{c}_{h}} u^{i}\left(c_{h}, \mathbf{c}^{-i}, c\right) \mathrm{d} F_{h}(c)\right. \\
& +\int_{\min \left\{\bar{c}_{l}, \underline{c}_{h}\right\}}^{\bar{c}_{l}} u^{i}\left(c_{h}, \mathbf{c}^{-i}, c\right) \mathrm{d} F_{l}(c) \\
& \left.+\int_{\underline{c}_{l}}^{\min \left\{\bar{c}_{l}, \underline{c}_{h}\right\}} u^{i}\left(c_{h}, \mathbf{c}^{-i}, \underline{c}_{h}\right)+Q\left(\underline{c}_{h}-c\right) X^{i}\left(c_{h}, \mathbf{c}^{-i}, \underline{c}_{h}\right) \mathrm{d} F_{l}(c)\right\} \\
& =U^{i}\left(c_{h}\right)+\sum_{\mathbf{c}^{-i}} \operatorname{Prob}\left(\mathbf{c}^{-i}\right) x^{i}\left(c_{h}, \mathbf{c}^{-i}\right)\left\{\Delta c-Q \int_{\underline{c}_{h}}^{\bar{c}_{h}} X^{i}\left(c_{h}, \mathbf{c}^{-i}, c\right) F_{h}(c) \mathrm{d} c\right. \\
& +Q 1_{\left\{\underline{c}_{h}<\bar{c}_{l}\right\}}\left\{\int_{\underline{c}_{h}}^{\bar{c}_{l}}\left(F_{l}(c)-F_{l}\left(\underline{c}_{h}\right)\right) X^{i}\left(c_{h}, \mathbf{c}^{-i}, c\right) \mathrm{d} c\right. \\
& \left.+\left(1-F_{l}\left(\underline{c}_{h}\right)\right) \int_{\bar{c}_{l}}^{\bar{c}_{h}} X^{i}\left(c_{h}, \mathbf{c}^{-i}, c\right) \mathrm{d} c+F_{l}\left(\underline{c}_{h}\right) \int_{\underline{c}_{h}}^{\bar{c}_{h}} X^{i}\left(c_{h}, \mathbf{c}^{-i}, c\right) \mathrm{d} c\right\} \\
& +Q 1_{\left\{\underline{c}_{h} \geq \bar{c}_{l}\right\}} \int_{\underline{c}_{h}}^{\bar{c}_{h}} X^{i}\left(c_{h}, \mathbf{c}^{-i}, c\right) \mathrm{d} c+Q X^{i}\left(c_{h}, \mathbf{c}^{-i}, \underline{c}_{h}\right) \int_{\underline{c}_{l}}^{\min \left\{\bar{c}_{l}, \underline{c}_{h}\right\}}\left(\underline{c}_{h}-c\right) \mathrm{d} c \\
& =U^{i}\left(c_{h}\right)+\sum_{\mathbf{c}^{-i}} \operatorname{Prob}\left(\mathbf{c}^{-i}\right) x^{i}\left(c_{h}, \mathbf{c}^{-i}\right)\left\{\Delta c+Q \int_{\underline{c}_{h}}^{\bar{c}_{h}} X^{i}\left(c_{h}, \mathbf{c}^{-i}, c\right)\left(F_{l}(c)-F_{h}(c)\right) \mathrm{d} c\right. \\
& \left.+Q X^{i}\left(c_{h}, \mathbf{c}^{-i}, \underline{c}_{h}\right) \int_{\underline{c}_{l}}^{\min \left\{\bar{c}_{l}, \underline{c}_{h}\right\}}\left(\underline{c}_{h}-c\right) \mathrm{d} c\right\} .
\end{aligned}
$$


Using the obtained expressions for $U^{i}\left(c_{h}\right)$ and $U^{i}\left(c_{l}\right)$, the expected buyer surplus is

$$
\begin{aligned}
\text { Sur }= & \sum_{i=1}^{n} \mu_{1}\left\{\sum _ { \mathbf { c } ^ { - i } } \operatorname { P r o b } ( \mathbf { c } ^ { - i } ) \cdot x ^ { i } ( c _ { l } , \mathbf { c } ^ { - i } ) \left\{R-c_{l}\right.\right. \\
& \left.\left.+\int_{\underline{c}_{l}}^{\bar{c}_{l}} Q \cdot(R-c) \cdot X^{i}\left(c_{l}, \mathbf{c}^{-i}, c\right) \mathrm{d} F_{l}(c)\right\}\right\} \\
& +\sum_{i=1}^{n}\left(1-\mu_{1}\right)\left\{\sum _ { \mathbf { c } ^ { - i } } P ( \mathbf { c } ^ { - i } ) \cdot x ^ { i } ( c _ { l } , \mathbf { c } ^ { - i } ) \left\{R-c_{h}-\frac{\mu_{1}}{1-\mu_{1}} \cdot \Delta c\right.\right. \\
& +Q \cdot \int_{\underline{c}_{h}}^{\bar{c}_{h}}\left(R-c-\frac{\mu_{1}}{1-\mu_{1}} \cdot \frac{F_{l}(c)-F_{h}(c)}{f_{h}(c)}\right) X^{i}\left(c_{h}, \mathbf{c}^{-i}, c\right) \mathrm{d} F_{h}(c) \\
& \left.\left.\quad Q \cdot \frac{\mu_{1}}{1-\mu_{1}} \cdot X^{i}\left(c_{h}, \mathbf{c}^{-i}, \underline{c}_{h}\right) \int_{\underline{c}_{l}}^{\min \left\{\underline{c}_{h}, \bar{c}_{l}\right\}}\left(\underline{c}_{h}-c\right) \mathrm{d} F_{l}(c)\right\}\right\}
\end{aligned}
$$

The buyer maximizes the latter expression with respect to $X^{i}\left(c_{l}, \mathbf{c}^{-i}, c\right), X^{i}\left(c_{h}, \mathbf{c}^{-i}, c\right)$ and the vectors $x(\mathbf{c})$, while respecting the monotonicity constraints implied by Lemma A.1. We have $R>\bar{c}_{l}$ by assumption and thus

$$
X^{i}\left(c_{l}, \mathbf{c}^{-i}, c\right) \equiv 1 \quad \text { for all } c \in\left[\underline{c}_{l}, \bar{c}_{l}\right]
$$

$X^{i}\left(c_{h}, \mathbf{c}^{-i}, c\right)$ has to be non-increasing by Lemma A.1 and takes values only in the interval [0,1]. Using similar arguments as used in static screening, e.g. Riley (1979), the term

$$
\int_{\underline{c}_{h}}^{\bar{c}_{h}}\left(R-c-\frac{\mu_{1}}{1-\mu_{1}} \cdot \frac{F_{l}(c)-F_{h}(c)}{f_{h}(c)}\right) \cdot X^{i}\left(c_{h}, \mathbf{c}^{-i}, c\right) \mathrm{d} F_{h}(c)
$$

is maximized for a step function. That is, there is a cutoff $c^{*} \in\left[\underline{c}_{h}, \bar{c}_{h}\right]$ such that

$$
X^{i}\left(c_{h}, \mathbf{c}^{-i}, c\right)= \begin{cases}X^{i}\left(c_{h}, \mathbf{c}^{-i}, \underline{c}_{h}\right), & c<c^{*} \\ 0, & c>c^{*}\end{cases}
$$

We still have to determine the optimal values $c^{*}$ and $X^{i}\left(c_{h}, \mathbf{c}^{-i}, \underline{c}_{h}\right)$. Using the prop- 
erties obtained so far, we get

$$
\begin{aligned}
\text { Sur }= & \sum_{i=1}^{n} \mu_{1}\left\{\sum_{\mathbf{c}^{-i}} \operatorname{Prob}\left(\mathbf{c}^{-i}\right) \cdot x^{i}\left(c_{l}, \mathbf{c}^{-i}\right)\left\{R-c_{l}+Q \cdot\left(R-\mathbb{E}_{l}(c)\right)\right\}\right\} \\
& +\sum_{i=1}^{n}\left(1-\mu_{1}\right)\left\{\sum _ { \mathbf { c } ^ { - i } } P ( \mathbf { c } ^ { - i } ) \cdot x ^ { i } ( c _ { l } , \mathbf { c } ^ { - i } ) \left\{R-c_{h}-\frac{\mu_{1}}{1-\mu_{1}} \cdot \Delta c\right.\right. \\
& +Q \cdot X^{i}\left(c_{h}, \mathbf{c}^{-i}, \underline{c}_{h}\right)\left[\int_{\underline{c}_{h}}^{c^{*}}\left(R-c-\frac{\mu_{1}}{1-\mu_{1}} \cdot \frac{F_{l}(c)-F_{h}(c)}{f_{h}(c)}\right) \mathrm{d} F_{h}(c)\right. \\
& \left.\left.\left.-\frac{\mu_{1}}{1-\mu_{1}} \cdot \int_{\underline{c}_{l}}^{\min \left\{\underline{c}_{h}, \bar{c}_{l}\right\}}\left(\underline{c}_{h}-c\right) \mathrm{d} F_{l}(c)\right]\right\}\right\} .
\end{aligned}
$$

Recall we seek to give conditions such that $c^{*}=\bar{c}_{h}$ and $X^{i}\left(c_{h}, \mathbf{c}^{-i}, \underline{c}_{h}\right)=1$. Clearly, a sufficient condition for $c^{*}=\bar{c}_{h}$ is given by

$$
\int_{\underline{c}_{h}}^{\bar{c}_{h}} R-c-\frac{\mu_{1}}{1-\mu_{1}} \cdot \frac{F_{l}(c)-F_{h}(c)}{f_{h}(c)} \mathrm{d} F_{h}(c) \geq \int_{\underline{c}_{h}}^{c^{*}} R-c-\frac{\mu_{1}}{1-\mu_{1}} \cdot \frac{F_{l}(c)-F_{h}(c)}{f_{h}(c)} \mathrm{d} F_{h}(c)
$$

for all $c^{*} \leq \bar{c}_{h}$. The latter is equivalent to

$$
R \geq R_{1}:=\sup _{c^{*}} \mathbb{E}_{h}\left(c \mid c \geq c^{*}\right)+\frac{\mu_{1}}{1-\mu_{1}} \cdot \frac{1}{1-F_{h}\left(c^{*}\right)} \cdot \int_{c^{*}}^{\bar{c}_{h}} F_{l}(c)-F_{h}(c) \mathrm{d} c .
$$

Lemma A.2. We have that $R_{1}<\infty$.

Proof. For all $\zeta \in\left[\underline{c}_{h}, \bar{c}_{h}\right]$ define the function $H$ via

$$
H(\zeta)=\mathbb{E}_{h}(c \mid c \geq \zeta)+\frac{\mu_{1}}{1-\mu_{1}} \cdot \frac{1}{1-F_{h}(\zeta)} \cdot \int_{\zeta}^{\bar{c}_{h}} F_{l}(c)-F_{h}(c) \mathrm{d} c .
$$

Observe that

$$
\begin{aligned}
\lim _{\zeta \rightarrow \bar{c}_{h}} H(\zeta) & =\bar{c}_{h}+\frac{\mu_{1}}{1-\mu_{1}} \cdot \lim _{\zeta \rightarrow \bar{c}_{h}} \frac{\int_{\zeta}^{\bar{c}_{h}} F_{l}(c)-F_{h}(c) \mathrm{d} c}{1-F_{h}(\zeta)} \\
& =\bar{c}_{h}+\frac{\mu_{1}}{1-\mu_{1}} \cdot \lim _{\zeta \rightarrow \bar{c}_{h}} \frac{F_{l}(\zeta)-F_{h}(\zeta)}{-f_{h}(\zeta)} \\
& =\bar{c}_{h}+\frac{\mu_{1}}{1-\mu_{1}} \cdot \frac{F_{l}\left(\bar{c}_{h}\right)-F_{h}\left(\bar{c}_{h}\right)}{-f_{h}\left(\bar{c}_{h}\right)}=\bar{c}_{h} .
\end{aligned}
$$

Now fix $\kappa>0$. By continuity, there is $\varepsilon>0$ such that $H(\zeta)<\bar{c}_{h}+\kappa$ for all $\zeta \in\left(\bar{c}_{h}-\varepsilon, \bar{c}_{h}\right]$. Lastly, for $\zeta \leq \bar{c}_{h}-\varepsilon$ we have

$$
H(\zeta) \leq \bar{c}_{h}+\frac{\mu_{1}}{1-\mu_{1}} \cdot \frac{1}{1-F_{h}(\zeta)} \cdot \int_{\zeta}^{\bar{c}_{h}} F_{l}(c)-F_{h}(c) \mathrm{d} c<\bar{c}_{h}+\frac{\mu_{1}}{1-\mu_{1}} \cdot \frac{1}{1-F_{h}\left(\bar{c}_{h}-\varepsilon\right)} .
$$


Thus, $H(\cdot)$ is uniformly bounded and $R_{1}=\sup _{\underline{c}_{h} \leq \zeta \leq \bar{c}_{h}} H(\zeta)<\infty$.

To guarantee that in addition $X^{i}\left(c_{h}, \mathbf{c}^{-i}, \underline{c}_{h}\right)=1$ it has to hold that

$$
\begin{aligned}
R & \geq \mathbb{E}_{h}(c)+\frac{\mu_{1}}{1-\mu_{1}} \cdot\left(\int_{\underline{c}_{h}}^{\bar{c}_{h}} F_{l}(c)-F_{h}(c) \mathrm{d} c+\int_{\underline{c}_{l}}^{\min \left\{\underline{c}_{h}, \bar{c}_{l}\right\}}\left(\underline{c}_{h}-c\right) \mathrm{d} F_{l}(c)\right) \\
& =\mathbb{E}_{h}(c)+\frac{\mu_{1}}{1-\mu_{1}} \cdot\left(\mathbb{E}_{h}(c)-\mathbb{E}_{l}(c)\right)=: R_{2} .
\end{aligned}
$$

Clearly, $R_{2}<\infty$. The virtual value from low-cost suppliers always exceeds that of high-cost suppliers. Hence, $x^{i}\left(c_{h}, \mathbf{c}^{-i}\right) \equiv 0$ if $c^{j}=c_{l}$ for some $j \neq i$. Furthermore, symmetry yields

$$
x^{i}\left(c_{l}, \mathbf{c}^{-i}\right)=\frac{1}{\#\left\{j \mid c^{j}=c_{l}\right\}},
$$

and $x^{i}\left(c_{h}, \ldots, c_{h}\right)=1 / n$ as long as

$$
R \geq R_{3}:=\frac{1}{1+Q} \cdot\left(c_{h}+\mathbb{E}_{h}(c)+\frac{\mu_{1}}{1-\mu_{1}} \cdot\left(\Delta c+\mathbb{E}_{h}(c)-\mathbb{E}_{l}(c)\right)\right)
$$

Again, it is clear that $R_{3}<\infty$. To summarize, if $R \geq R^{c}:=\max \left\{R_{1}, R_{2}, R_{3}\right\}$ the optimal mechanism under full commitment implements the efficient allocation. To implement this allocation the buyer uses a second-price auction with bid space $\left\{b_{l}, b_{h}\right\}$, where

$$
\begin{aligned}
b_{l} & =c_{l}+Q \cdot \mathbb{E}_{l}(c)-\left(1-\mu_{1}\right)^{n-1} \cdot \frac{n-1}{n \cdot \operatorname{Prob}\left(\mu_{1}\right)}\left(\Delta c+Q \cdot\left(\mathbb{E}_{h}(c)-\mathbb{E}_{l}(c)\right)\right), \\
b_{h} & =c_{h}+Q \mathbb{E}_{h}(c),
\end{aligned}
$$

and in which low-cost suppliers bid $b_{l}$, while high-cost suppliers bid $b_{h}$. Here,

$$
\operatorname{Prob}\left(\mu_{1}\right)=\sum_{k=1}^{n-1} \mu_{1}^{k} \cdot\left(1-\mu_{1}\right)^{n-1-k}\left(\begin{array}{c}
n-1 \\
k
\end{array}\right) \cdot \frac{1}{k+1}
$$

denotes the probability of winning the auction and receiving the payment $b_{l}$, when actually bidding $b_{l}$. Under full commitment, the supplier is forced to continue production in period two without additional payments. Equivalently, we can set up a payment scheme such that the supplier receives a payment always covering her production costs also in period two. The expected value of this payment needs to be subtracted from the respective bids $b_{l}$ and $b_{h}$. It remains to be shown that the second-price auction has the described equilibrium. Consider first a high-cost supplier. Bidding $b_{h}$ yields 
expected utility of zero. Bidding $b_{l}$ yields

$$
\begin{aligned}
& \left(1-\mu_{1}\right)^{n-1} \cdot\left(b_{h}-c_{h}-Q \cdot \mathbb{E}_{h}(c)\right)+\operatorname{Prob}\left(\mu_{1}\right) \cdot\left(b_{l}-c_{h}-Q \cdot \mathbb{E}_{h}(c)\right) \\
= & -\left(\left(1-\mu_{1}\right)^{n-1} \cdot \frac{n-1}{n}+\operatorname{Prob}\left(\mu_{1}\right)\right)\left(\Delta c+Q \cdot\left(\mathbb{E}_{h}(c)-\mathbb{E}_{l}(c)\right)\right) \\
< & 0 .
\end{aligned}
$$

A low-cost supplier obtains $\frac{\left(1-\mu_{1}\right)^{n-1}}{n} \cdot\left(\Delta c+Q \cdot\left(\mathbb{E}_{h}(c)-\mathbb{E}_{l}(c)\right)\right)$ from bidding $b_{h}$. Bidding $b_{l}$ yields

$$
\begin{aligned}
& \left(1-\mu_{1}\right)^{n-1} \cdot\left(b_{h}-c_{l}-Q \cdot \mathbb{E}_{l}(c)\right)+\operatorname{Prob}\left(\mu_{1}\right) \cdot\left(b_{l}-c_{l}-Q \cdot \mathbb{E}_{l}(c)\right) \\
= & \left(1-\mu_{1}\right)^{n-1} \cdot\left(\Delta c+Q \cdot\left(\mathbb{E}_{h}(c)-\mathbb{E}_{l}(c)\right)\right) \\
& \quad-\left(\frac{n-1}{n} \cdot\left(1-\mu_{1}\right)^{n-1}\right)\left(\Delta c+Q \cdot\left(\mathbb{E}_{h}(c)-\mathbb{E}_{l}(c)\right)\right) \\
= & \frac{\left(1-\mu_{1}\right)^{n-1}}{n} \cdot\left(\Delta c+Q \cdot\left(\mathbb{E}_{h}(c)-\mathbb{E}_{l}(c)\right)\right) .
\end{aligned}
$$

\section{Proof of Lemma 5.}

ad i) Suppose $\bar{c}_{l}=\bar{c}_{h}$. Define

$$
R^{L}:=\sup _{\underline{c}_{l} \leq \zeta \leq \bar{c}_{l}=\bar{c}_{h}} \frac{\bar{c}_{h}-\zeta F_{l}(\zeta)}{1-F_{l}(\zeta)} .
$$

We have that

$$
\lim _{\zeta \rightarrow \bar{c}_{h}} \frac{\bar{c}_{h}-\zeta \cdot F_{l}(\zeta)}{1-F_{l}(\zeta)}=\lim _{\zeta \rightarrow \bar{c}_{h}} \frac{-F_{l}(\zeta)-\zeta \cdot f_{l}(\zeta)}{-f_{l}(\zeta)}=\frac{1+\bar{c}_{h} \cdot f_{l}\left(\bar{c}_{h}\right)}{f_{l}\left(\bar{c}_{h}\right)}<\infty
$$

Let $\kappa>0$. By continuity, there is $\varepsilon>0$ such that $\frac{\bar{c}_{h}-\zeta \cdot F_{l}(\zeta)}{1-F_{l}(\zeta)}<\frac{1+\bar{c}_{h} \cdot f_{l}\left(\bar{c}_{h}\right)}{f_{l}\left(\bar{c}_{h}\right)}+\kappa$ for all $\zeta \in\left(\bar{c}_{h}-\varepsilon, \bar{c}_{h}\right]$. Furthermore, for all $\zeta \leq \bar{c}_{h}-\varepsilon$ we have

$$
\frac{\bar{c}_{h}-\zeta \cdot F_{l}(\zeta)}{1-F_{l}(\zeta)} \leq \frac{\bar{c}_{h}}{1-F_{l}\left(\bar{c}_{h}-\varepsilon\right)}<\infty
$$

Consequently, $R^{L}<\infty$. When $R>R^{L}$ we have that $(R-c) \cdot F_{l}(c) \leq\left(R-\bar{c}_{h}\right) \cdot F_{l}\left(\bar{c}_{h}\right)=$ $R-\bar{c}_{h}$ for all $c \in\left[\underline{c}_{l}, \bar{c}_{h}\right]$. By first-order stochastic dominance we have that for any belief $\mu \in[0,1]$ and any $c \leq \bar{c}_{h}$ the following holds true

$$
(R-c) \cdot\left[\mu \cdot F_{l}(c)+(1-\mu) \cdot F_{h}(c)\right] \leq(R-c) \cdot F_{l}(c) \leq R-\bar{c}_{h}
$$


Hence, following any belief $\mu$ the buyer optimally offers to pay $\bar{c}_{h}$ for the additional delivery of $Q$ units in period two. In words, shutdown in period two never occurs in equilibrium. Thus, a second-price auction implements the efficient allocation as shown in Proposition 1.

ad ii) Suppose $\bar{c}_{l}<\bar{c}_{h}$. Consider the $\alpha$-second-price auction with bid space $\left\{b_{l}, b_{h}\right\}$. We derive conditions such that this auction exhibits an equilibrium where type $\theta$ supplier bids $b_{\theta}$ and the production always continues in period two. Given the proposed equilibrium strategies of the suppliers, the equilibrium beliefs are $\mu^{l}=1$ (if the winner's payment is $b_{l}$ or the mechanism revealed the winning bid $b_{l}$ ) or

$$
\mu^{h}=\frac{(1-\alpha) \cdot \mu_{1}}{1-\alpha \cdot \mu_{1}}
$$

otherwise. Continued production requires that

1) $R-\bar{c}_{l} \geq(R-c) \cdot F_{l}(c)$ for all $c \in\left[\underline{c}_{l}, \bar{c}_{l}\right]$,

2) $R-\bar{c}_{h} \geq(R-c) \cdot\left(\mu^{h} \cdot F_{l}(c)+\left(1-\mu^{h}\right) \cdot F_{h}(c)\right)$ for all $c \in\left[\underline{c}_{l}, \bar{c}_{h}\right]$.

To satisfy 1) it has to hold that

$$
R \geq R^{l}:=\sup _{\underline{c}_{l} \leq c \leq \bar{c}_{l}} \frac{\bar{c}_{l}-c \cdot F_{l}(c)}{1-F_{l}(c)} .
$$

In the previous case we have already shown that $R^{l}<\infty$. To satisfy 2 ) it has to hold that

$$
R \geq R^{h}(\alpha):=\sup _{\underline{c}_{l} \leq c \leq \bar{c}_{h}} c+\frac{\bar{c}_{h}-c}{1-F_{h}(c)-\frac{(1-\alpha) \cdot \mu_{1}}{1-\alpha \cdot \mu_{1}} \cdot\left(F_{l}(c)-F_{h}(c)\right)} .
$$

Note that

$$
\begin{aligned}
\lim _{c \rightarrow \bar{c}_{h}} R^{h}(\alpha) & =\bar{c}_{h}+\lim _{c \rightarrow \bar{c}_{h}} \frac{-1}{-f_{h}(c)-\frac{(1-\alpha) \cdot \mu_{1}}{1-\alpha \cdot \mu_{1}} \cdot\left(f_{l}(c)-f_{h}(c)\right)} \\
& =\bar{c}_{h}+\frac{1}{\frac{1-\mu_{1}}{1-\alpha \cdot \mu_{1}} f_{h}\left(\bar{c}_{h}\right)+\frac{(1-\alpha) \cdot \mu_{1}}{1-\alpha \cdot \mu_{1}} f_{l}\left(\bar{c}_{h}\right)}<\infty .
\end{aligned}
$$

Using this observation and similar arguments as before, this establishes $R^{h}(\alpha)<\infty$ for all $\alpha \in[0,1]$. Note that as $\alpha$ increases the term $\frac{(1-\alpha) \cdot \mu_{1}}{1-\alpha \cdot \mu_{1}}$ decreases and thus $R^{h}(\alpha)$ decreases as well. Taken together, for all $\alpha \in[0,1]$ there is a $R^{\neq}(\alpha)$ such that no shutdown occurs following the described bidding behavior in a $\alpha$-second-price auction.

We next give a condition such that suppliers indeed follow the described bidding 
strategy. A high-cost supplier prefers bidding $b_{h}$ whenever

$$
\begin{aligned}
& \frac{\left(1-\mu_{1}\right)^{n-1}}{n} \cdot\left(b_{h}-c_{h}+Q \cdot\left(c_{h}-\mathbb{E}_{h}(c)\right)\right) \\
\geq & \left(1-\mu_{1}\right)^{n-1} \cdot\left(b_{h}-c_{h}+\alpha \cdot Q \cdot \int_{\underline{c}_{h}}^{\bar{c}_{l}}\left(\bar{c}_{l}-c\right) \mathrm{d} F_{h}(c)+(1-\alpha) \cdot Q \cdot\left(\bar{c}_{h}-\mathbb{E}_{h}(c)\right)\right) \\
& +P\left(\mu_{1}\right) \cdot\left(b_{l}-c_{h}+Q \cdot \int_{\underline{c}_{h}}^{\bar{c}_{l}}\left(\bar{c}_{l}-c\right) \mathrm{d} F_{h}(c)\right) .
\end{aligned}
$$

A low-cost supplier prefers bidding $b_{l}$ whenever

$$
\begin{aligned}
& \left(1-\mu_{1}\right)^{n-1} \cdot\left(b_{h}-c_{l}+Q \cdot\left(\alpha \cdot \bar{c}_{l}+(1-\alpha) \cdot \bar{c}_{h}-\mathbb{E}_{l}(c)\right)\right) \\
& +P\left(\mu_{1}\right) \cdot\left(b_{l}-c_{l}+Q \cdot\left(\bar{c}_{l}-\mathbb{E}_{l}(c)\right)\right) \geq \\
& \frac{\left(1-\mu_{1}\right)^{n-1}}{n} \cdot\left(b_{h}-c_{l}+Q \cdot\left(c_{h}-\mathbb{E}_{l}(c)\right)\right) .
\end{aligned}
$$

Adding these constraints yield the necessary condition $\alpha \leq \bar{\alpha}$, where

$$
\begin{aligned}
\bar{\alpha} \cdot Q \cdot \int_{\bar{c}_{l}}^{\bar{c}_{h}}\left(c-\bar{c}_{l}\right) \mathrm{d} F_{h}(c)= & \left(P\left(\mu_{1}\right)+\frac{n-1}{n} \cdot\left(1-\mu_{1}\right)^{n-1}\right) \cdot \Delta c \\
& +\frac{n-1}{n} \cdot\left(1-\mu_{1}\right)^{n-1} \cdot Q \cdot\left(\mathbb{E}_{h}(c)-\mathbb{E}_{l}(c)\right) \\
& +P\left(\mu_{1}\right) \cdot \int_{\underline{c}_{l}}^{\bar{c}_{l}}\left(\bar{c}_{l}-c\right) \cdot\left(f_{l}(c)-f_{h}(c)\right) \mathrm{d} c .
\end{aligned}
$$

The right-hand side is strictly positive, hence $\bar{\alpha}>0$. Hence, the $\alpha$-second-price auction implements the efficient allocation whenever $\alpha \leq \bar{\alpha}$ and $R \geq R^{\neq}(\alpha)$. Taken together, there is some $\alpha$ such that the $\alpha$-second-price auction implements the efficient allocation whenever $R \geq R^{\neq}(\min \{1, \bar{\alpha}\})=: R^{\neq}$. A regular second-price auction implements the efficient allocation whenever $R \geq R^{\neq}(1)=: \widehat{R}^{\neq}>R^{\neq}$.

\section{Proof of Proposition 8.}

For all auctions defined in the proof of Lemma 5 set $b_{h}=\bar{c}_{h}-Q \cdot\left(\bar{c}_{h}-\mathbb{E}_{h}(c)\right)$, and determine $b_{l}$ from the binding incentive constraint of the low-cost supplier. Our conditions on implementability ensure that both participation and incentive constraints are satisfied. In the resulting equilibrium a high-cost type's expected profit is zero, 
while a low-cost type's expected profit is

$$
\frac{\left(1-\mu_{1}\right)^{n-1}}{n} \cdot\left(\Delta c+Q \cdot\left(\mathbb{E}_{h}(c)-\mathbb{E}_{l}(c)\right)\right)
$$

Thus, the suppliers' rents equal those in the optimal mechanism under full commitment. Additionally, the same allocation is implemented. Consequently, the same buyer-surplus obtains.

\section{B Quantal response equilibrium in the experiment}

In order to shed more light on the deviations from the equilibrium bidding behavior, we estimate a logit quantal response model (QRE), which allows us to compare noise in the bidding behavior between treatments. The QRE concept was first introduced by McKelvey and Palfrey (1995) and can be interpreted in a way that individuals do not always take the best action available, but play better actions more often. This means the probability with which a certain action is played is determined by the expected utility associated with this action. This is sometimes referred to as noisy decision making.

We consider a logit QRE assuming that subjects have a logit choice function. Consider a subject with a discrete choice set of possible action $S=\left\{s_{1}, \cdots, s_{n}\right\}$ and let $U\left(s_{j}\right)$ with $s_{j} \in S$ denote the expected utility associated with the choice of action $s_{j}$. Then the probability of playing action $s_{j}$ is given by

$$
\operatorname{Pr}\left(s_{j}\right)=\frac{e^{\lambda \cdot U\left(s_{j}\right)}}{\sum_{k=1}^{n} e^{\lambda \cdot U\left(s_{k}\right)}} .
$$

The parameter $\lambda>0$ is often referred to as the precision parameter and determines the shape of the probability distribution. The smaller the $\lambda$, the larger the noise and the more probability mass is on worse compared to better decisions. Table 2 reports the maximum likelihood estimates for the different procurement mechanisms. Once separately for each of the 18 cohorts and once for each procurement mechanism as a whole.

The analysis shows that the noise associated with the observed bidding behavior in smallest in the FPA1 treatment and largest in the SPA2 treatment. 
Table 2: Quantal response equilibrium estimates.

\begin{tabular}{c|c|c|c}
\hline \hline Cohort number & $\lambda_{F P A 1}$ & $\lambda_{F P A 2}$ & $\lambda_{S P A 2}$ \\
\hline 1 & 0.2115 & 0.3086 & 0.1910 \\
2 & 0.3604 & 0.3136 & 0.2451 \\
3 & 0.4773 & 0.3376 & 0.2586 \\
4 & 0.4825 & 0.3460 & 0.2837 \\
5 & 0.5373 & 0.3688 & 0.3224 \\
6 & 0.6130 & 0.5427 & 0.5015 \\
\hline All & 0.4082 & 0.3521 & 0.2873 \\
\hline \hline
\end{tabular}

Notes: Reported are the maximum-likelihood estimates for the precision parameter $\lambda$ for each independent cohort and for each treatment as a whole. The estimates are largest for the FPA1 and lowest for the SPA2, however, the distribution of the estimates does not differ significantly between the different procurement mechanisms ( $p=0.1129$, Kruskal-Wallis test). 
Download ZEW Discussion Papers from our ftp server:

http://ftp.zew.de/pub/zew-docs/dp/

or see:

https://www.ssrn.com/link/ZEW-Ctr-Euro-Econ-Research.html

https://ideas.repec.org/s/zbw/zewdip.html

$$
\text { / / }
$$

ZEW - Leibniz-Zentrum für Europäische Wirtschaftsforschung GmbH Mannheim

ZEW - Leibniz Centre for European

Economic Research

L 7,1 68161 Mannheim · Germany

Phone +49621 1235-01

info@zew.de.zew.de

Discussion Papers are intended to make results of ZEW research promptly available to other economists in order to encourage discussion and suggestions for revisions. The authors are solely responsible for the contents which do not necessarily represent the opinion of the ZEW. 